OPEN ACCESS

Edited by:

Elizabeth B. Torres,

Rutgers University, The State University of New Jersey,

United States

Reviewed by:

Limor Avivi-Arber,

University of Toronto, Canada Barry Sessle,

University of Toronto, Canada

${ }^{*}$ Correspondence:

Michael R. Borich

michael.borich@emory.edu

${ }^{\dagger}$ These authors have contributed equally to this work

Received: 28 January 2019 Accepted: 03 May 2019

Published: 22 May 2019

Citation:

Edwards LL, King EM, Buetefisch CM and Borich MR (2019) Putting the "Sensory" Into Sensorimotor Control: The Role of Sensorimotor Integration in Goal-Directed Hand Movements After Stroke. Front. Integr. Neurosci. 13:16. doi: 10.3389/fnint.2019.00016

\section{Putting the "Sensory" Into Sensorimotor Control: The Role of Sensorimotor Integration in Goal-Directed Hand Movements After Stroke}

\author{
Lauren L. Edwards ${ }^{1 \dagger}$, Erin M. King ${ }^{1 \dagger}$, Cathrin M. Buetefisch ${ }^{2,3,4}$ and Michael R. Borich ${ }^{2 *}$ \\ ${ }^{1}$ Neuroscience Graduate Program, Graduate Division of Biological and Biomedical Sciences, Emory University, Atlanta, GA, \\ United States, ${ }^{2}$ Department of Rehabilitation Medicine, Laney Graduate School, Emory University, Atlanta, GA, United States, \\ ${ }^{3}$ Department of Neurology, Emory University, Atlanta, GA, United States, ${ }^{4}$ Department of Radiology and Imaging Sciences, \\ School of Medicine, Emory University, Atlanta, GA, United States
}

Integration of sensory and motor information is one-step, among others, that underlies the successful production of goal-directed hand movements necessary for interacting with our environment. Disruption of sensorimotor integration is prevalent in many neurologic disorders, including stroke. In most stroke survivors, persistent paresis of the hand reduces function and overall quality of life. Current rehabilitative methods are based on neuroplastic principles to promote motor learning that focuses on regaining motor function lost due to paresis, but the sensory contributions to motor control and learning are often overlooked and currently understudied. There is a need to evaluate and understand the contribution of both sensory and motor function in the rehabilitation of skilled hand movements after stroke. Here, we will highlight the importance of integration of sensory and motor information to produce skilled hand movements in healthy individuals and individuals after stroke. We will then discuss how compromised sensorimotor integration influences relearning of skilled hand movements after stroke. Finally, we will propose an approach to target sensorimotor integration through manipulation of sensory input and motor output that may have therapeutic implications.

Keywords: sensorimotor integration, motor learning, motor control, stroke, sensation

\section{INTRODUCTION}

Goal-directed movements of the hand are required to perform most tasks of daily living, such as tying a shoe, buttoning a shirt, and typing, among others. These highly coordinated voluntary movements involve interacting with and manipulating objects in the environment and rely on sensorimotor integration. Sensorimotor integration is the ability to incorporate sensory inputs that provide information about one's body and the external environment to inform and shape motor output (Wolpert et al., 1998). More specifically, sensory inputs for goal-directed hand movements provide information in an egocentric reference frame detailing location, size, weight, and shape of an object. In addition, kinematic information 
about the hand and upper extremity, including the trajectory needed to interact with the object, is provided. Successful integration of information contributes to generating the most efficient motor plan to execute a given task. Additionally, ongoing sensory feedback during motor performance refines the motor plan to optimize current and future performance. This process of sensorimotor integration is often disrupted in neurological disorders, such as stroke.

Stroke is defined as infarction of central nervous system tissue attributable to ischemia, based on neuropathological, neuroimaging, and/or clinical evidence of permanent injury (Sacco et al., 2013). Stroke is the fourth leading cause of death and remains the number one leading cause of long-term adult disability (Benjamin et al., 2017). Furthermore, the loss of productivity after stroke currently costs the United States an average of $\$ 33.9$ billion per year and is expected to reach $\$ 56$ billion by 2030 (Ovbiagele et al., 2013), making stroke a public health crisis. A primary contributor to persistent disability after stroke is incomplete motor recovery (Lai et al., 2002). Spontaneous biological recovery of motor function occurs during the first months after stroke (Cramer, 2008), underlying a current emphasis on intensive early intervention, although results are often mixed and complex (Bernhardt et al., 2017a). Despite intensive therapy, upper extremity impairment resolves up to $70 \%$ of baseline function for a given patient with some patients showing even less recovery than predicted (Winters et al., 2015). Most stroke survivors are left with a limited ability to perform skilled hand movements necessary for daily functioning (Lang et al., 2013). To reduce disability after stroke, there is a need to improve our understanding of the neuronal network physiology necessary to regain skilled functional hand use.

Currently, the field has primarily investigated motor deficits and motor learning with limited consideration of the role of sensory information, even though it is recognized that integration of sensory information is a critical component of motor control (Borich et al., 2015; Bolognini et al., 2016). Furthermore, evidence has shown that sensory input is important for recovery after stroke. In a systematic review, Meyer et al. found that across six studies, the extent of deficits in proprioception and light touch of the arm and hand were significantly related to recovery after stroke (Meyer et al., 2014). Despite evidence that sensory input is a critical component to motor execution, research nomenclature has been primarily focused on motor characteristics post-stroke and has therefore not capitalized fully on the information a sensorimotor perspective could provide. This observation is supported by a literature search showing an emphasis towards motor recovery and learning after stroke, over sensorimotor recovery and learning, with limited focus on sensorimotor integration (Figure 1). While it is possible that authors may use these terms interchangeably, the literature search terminology suggests that there is potential bias towards motor contributions. Therefore, there is an important gap in our understanding of the contributions of sensorimotor integration to recovery.

In the following brief review, we will highlight the importance of processing and integrating sensory and motor

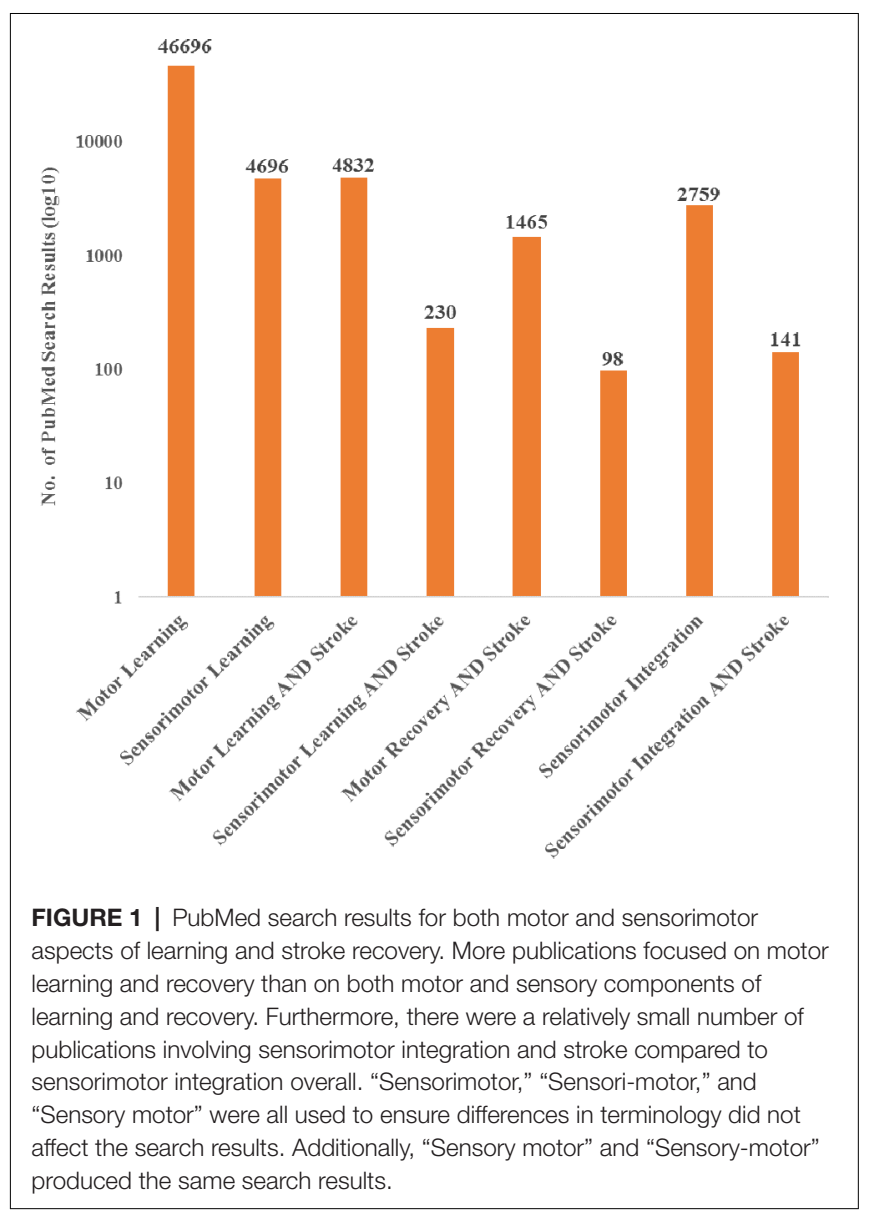

information that underlies skill performance and learning with an emphasis on skilled hand movements in stroke. We will focus primarily on three cortical regions: primary motor cortex (M1), posterior parietal cortex (PPC) and primary somatosensory cortex (S1) while briefly mentioning other cortical and subcortical brain areas also involved in sensorimotor integration. These brain regions are highlighted due to our focus on the integration of sensory and motor information at the level of the cortex, but also because these cortical areas receive blood supply from the middle cerebral artery (MCA), which is the most common type of stroke (Walcott et al., 2014). Furthermore, all three brain regions contribute to the corticospinal tract (CST) that provide necessary contributions to executing and controlling skilled hand movements routinely used in daily life. It should be noted that strokes occur in other brain regions but usually have less of an impact on sensorimotor integration underlying goal-directed, skilled hand movements and are outside the primary scope of this review article.

In the first section of this review article, we will discuss the role of sensorimotor integration via M1, PPC, and S1 in normal, skilled hand movements. We will then discuss how sensorimotor integration is affected by stroke and how impaired sensorimotor integration can impact relearning of skilled hand movements. Last, we propose an approach to target sensorimotor integration 
by manipulating sensory input and restricting motor output that may have therapeutic implications for stroke recovery.

\section{THE ROLE OF M1 IN GOAL-DIRECTED HAND MOVEMENTS}

\section{M1 Involvement in Movement Execution}

The M1 has a critical role in the execution of voluntary movements. Upper extremity movement execution is particularly dependent on descending output from M1 through the spinal cord to upper limb muscles. Pyramidal neurons in layer 5 have axons that are bundled together as a significant portion of the CST, where $85 \%-90 \%$ of the fibers decussate in the pyramids to provide control to the hand contralateral to the hemisphere of the M1 (Rosenzweig et al., 2009). The remaining fibers, approximately $10 \%-15 \%$, maintain ipsilateral projections that have a minor role in distal extremity motor control (Zaaimi et al., 2012). Of the neurons terminating in the spinal cord, some neurons will indirectly influence movements by synapsing onto interneurons in the intermediate zone (Rathelot and Strick, 2009) whereas direct control arises from the cortico-motoneuronal (CM) cells that terminate monosynaptically on $\alpha$-motoneurons in the ventral horn of the spinal cord (Lemon et al., 1986). These $\alpha$-motoneurons innervate skeletal muscle to control contralateral muscle contractions, and subsequently, voluntary movements (Rathelot and Strick, 2009; Schieber, 2011). The most abundant projections from $\mathrm{M} 1$ are to motor neurons that innervate hand muscles allowing for direct and individualized control of fingers required for complex and skilled hand movements (Dum and Strick, 1996). A lesion to these CST axonal fibers is the leading cause of motor disability and specifically causes loss in individualized finger function (Lawrence and Kuypers, 1968; Lemon, 2008), reiterating the importance of this connection from M1 to the $\alpha$-motoneurons innervating muscles of the hand. While CST is the largest contributor to skilled hand movement, there are other pathways, such as the reticulospinal tract, that offer additional contributions to certain aspects of hand function (for review, see Baker, 2011). The topographical organization of M1 demonstrates a larger spatial representation for the hand reflecting the relative importance of the output from CM cells to the hand (Penfield and Boldrey, 1937). The populations of CM cells in M1 fire differentially to allow for a variety of functional uses of the hand (Griffin et al., 2015). Within these populations, individual neurons can be tuned to preferentially code for single or multiple fingers or more proximal joints (Kirsch et al., 2014), and the kinematics of a movement, such as direction, force, and speed are also encoded (Georgopoulos et al., 1982, 1992; Mahan and Georgopoulos, 2013). This level of specification in M1 neuronal tuning allows for the execution of an extensive repertoire of complex hand movements.

As mentioned previously, the execution of skilled hand movements by M1 requires sensory information. Representations of the external environment must be generated from visual, proprioceptive, and tactile input (Makino et al., 2016), and these representations are combined with internal representations of the motor system, such as hand position, to create an internal model (Blakemore et al., 1998). Both external and internal representations have inherent variability that can be reduced by incorporating input from multiple sensory modalities (Körding and Wolpert, 2004).

Successful multisensory integration contributes to execution of a motor command that results in the desired movement outcome. For instance, if the goal is to button a shirt, the internal model should include the position of the button and buttonhole and starting position of the hand. These positions are determined by visual, proprioceptive, and tactile information that will be processed through PPC [visual (Kaas et al., 2011)] and S1 [proprioceptive, tactile (Kim et al., 2015), and nociceptive (Liang et al., 2011)], Sensory information associated with manipulation of the button will also be provided. The relevant sensory information is then relayed to $\mathrm{M} 1$, where a motor command is generated. This internal model will also be influenced by prior motor execution that contributes to development of an efference copy of the motor output (von Holst and Mittelstaedt, 1950). Using this information, an internal model includes predictions about expected sensory feedback resulting from the generated movement (Flanagan et al., 2006). In this example, if the button is not at the correct angle required for it to go through the button hole, or if the hand is in the incorrect starting position, the sensory reafferent information occurring in response to movement will not align with the predicted feedback generated from the efference copy (von Holst and Mittelstaedt, 1950). Therefore, the predicted sensory consequence will be updated, the model adapted, and subsequently, the error will be corrected by adjusting the motor command (Shadmehr et al., 2010).

There are several brain regions involved in sensorimotor integration for goal-directed hand movements (Figure 2). Non-cortical structures contributing to sensorimotor integration include the: basal ganglia (Nagy et al., 2006), cerebellum (Proville et al., 2014), and thalamus (Mo and Sherman, 2019). In rodents and primates, it has been shown that distinct subdivisions of the thalamus receive input from the basal ganglia and cerebellar nuclei and project to M1 (Bosch-Bouju et al., 2013; Bopp et al., 2017). The ventroanterior and ventromedial nuclei receive information from the basal ganglia, typically through GABAergic projections. The ventrolateral nucleus receives glutamatergic projections from cerebellar nuclei. In addition to these motor thalamic regions, there has been evidence from rodent models to suggest that sensory thalamic regions, such as the posterior medial nucleus, project directly to M1 (Ohno et al., 2012; Hooks et al., 2013, 2015). However, it is unclear whether these specific pathways are present in humans and non-human primates.

Here, our main focus is on sensory signals from PPC and S1 that convey pertinent information about somatosensation, proprioception, and visuomotor transformations to M1. The ability to transform visual and proprioceptive information about the location and space of the internal and external world is important to inform motor commands (Burnod et al., 1992). M1 neurons fire in response to both visual and proprioceptive stimuli (for review, see Hatsopoulos and Suminski, 2011). The M1 hand area is separated into caudal (M1c) and rostral (M1r) subregions: CM cells primarily arise from M1c and 


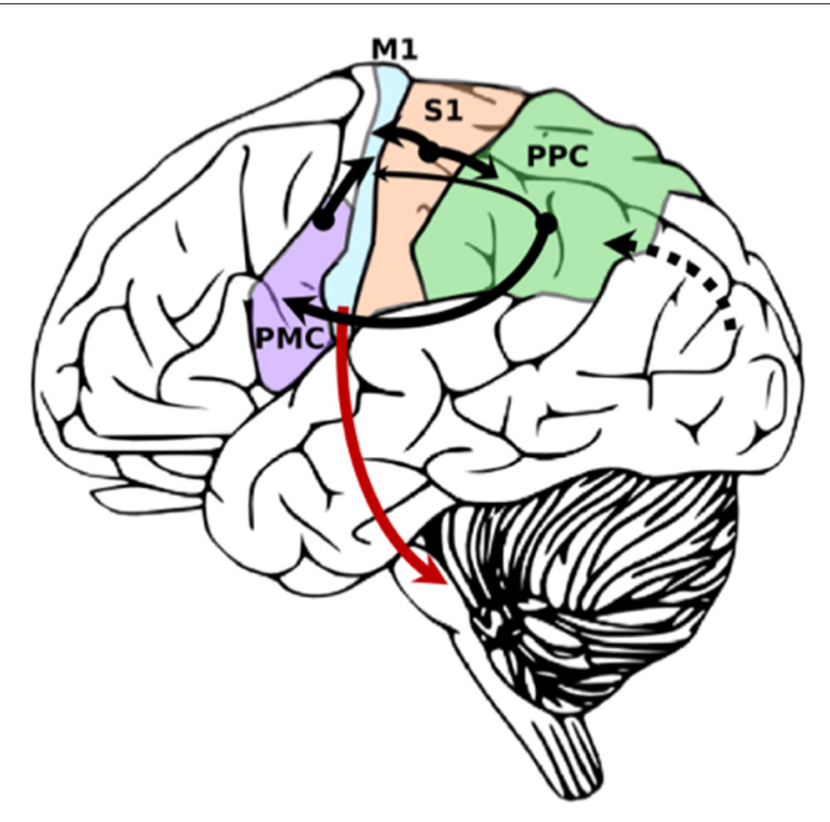

FIGURE 2 | Simplified diagram demonstrating primary sensory inputs to primary motor cortex. Cortico-cortical connections are black. Cortico-fugal projections from $\mathrm{M} 1$ are red. Width of arrow denotes strength of connection. Dotted line denotes primary visual input from visual cortex into posterior parietal cortex (PPC) for multimodal integration.

provide direct control of movements of the hand and distal forearm, whereas neurons in M1r influence motor control indirectly using interneurons in the spinal cord (Rathelot and Strick, 2009). Recent work suggests that this rostral and caudal subdivision of the M1 hand area also exists in humans and maintains differences in function (Viganò et al., 2019). S1 has strong reciprocal connections with M1c, whereas PPC has comparatively weaker connections to M1r (Stepniewska et al., 1993). Lesions made independently to M1c and M1r in adult squirrel monkeys produced different deficits, where M1c lesions resulted in cutaneous sensory deficits, and M1r lesions produced errors in aiming of the hand (Friel et al., 2005). These results are not only consistent with the sensory inputs that are expected to arise from PPC and S1 but show the importance of sensorimotor integration such that different regions of $\mathrm{M} 1$ specialize in integrating the unique sensory information provided by PPC and S1. Furthermore, proprioceptive and visual inputs to input to M1 will be weighted differently depending on the goal of the task (Sober and Sabes, 2003) further attesting to the dynamic nature of sensorimotor integration in M1.

\section{M1 Plasticity and Sensorimotor Learning}

In addition to the role of M1 in the production of movement, M1 also undergoes substantial plasticity, which has a critical role for learning skilled movements. Here, we define "motor learning" as an improvement in motor skill beyond baseline performance leading to a reduction in performance error that is retained over time (Shmuelof et al., 2012). Given that an error signal is inherently tied to sensory feedback and therefore needed for the learning of motor skills guided by sensory information (for review, see Seidler et al., 2013), we refer to motor learning as sensorimotor learning. Sensorimotor learning has been shown to induce functional and structural changes in M1 in rodents (Kleim et al., 1998) and non-human primates (Nudo et al., 1996a). In rodents, compared to practicing an unskilled lever-pressing task, practicing a skilled task that required specific paw manipulations to retrieve food pellets resulted in larger changes in M1 motor map representation of the forelimb, demonstrating that sensorimotor learning induces M1 plasticity (Kleim et al., 1998). M1 plasticity is defined as lasting changes in the morphological and/or functional properties of M1 (Sanes and Donoghue, 2000); experience-dependent plasticity is when these changes occur in response to life experiences, such as stroke (Kleim and Jones, 2008). In the rodent M1, plasticity underlying sensorimotor learning occurs through mechanisms of synaptic long-term potentiation (LTP) and long-term depression (LTD; RioultPedotti et al., 2000). Similar to these results from rodent studies, the involvement of an LTP-like mechanism has been also demonstrated in plastic changes of M1 when adult humans practice ballistic thumb movements (Bütefisch et al., 2000). Importantly, in non-human primates, changes in M1 motor map representation of the distal forelimb were specific to skilled motor learning, whereas performing repetitive unskilled movements alone was not sufficient to induce changes in motor representations (Plautz et al., 2000). Additionally, disrupting M1 activity in humans with transcranial magnetic stimulation (TMS) immediately after motor practice can disrupt memory consolidation for that skill (Muellbacher et al., 2002b; Robertson, 2004) resulting in reduced learning, indicating the importance of $\mathrm{M} 1$ in the early consolidation of motor learning. The role of M1 plasticity in sensorimotor learning has also been demonstrated in the orofacial representations in humans (Arima et al., 2011) and nonhuman primates (Arce-McShane et al., 2014).

LTP in M1 is considered a primary synaptic process involved in the experience-dependent plasticity that underlies sensorimotor learning (Kleim et al., 1998; Bütefisch et al., 2000; Sanes and Donoghue, 2000; Ziemann et al., 2004; Nudo, 2013). At the synaptic level, a bidirectional range of dynamic modifiability exists, such that a synapse experiences a limited amount of synaptic strengthening (LTP) or reduction in strength (LTD; Rioult-Pedotti et al., 2000). The ability of a synapse to maintain a target range of modifiability to prevent over- or under-excitation of the neural circuit is referred to as homeostatic metaplasticity (Whitt et al., 2014). Evidence of synaptic metaplasticity suggests that prior history of synaptic plasticity influences the degree of future synaptic modification (Abraham and Bear, 1996). For instance, a synapse that is close to the upper limit of synaptic modifiability would not experience the same degree of LTP induction as a synapse farther away from its upper limit (Figure 3). Previous electrophysiological evidence from in vitro studies suggests that inducing LTD at a synapse, bringing it farther from its upper limit of modifiability, enhances the capacity for subsequent LTP induction (Rioult-Pedotti et al., 2000). This same principle has been demonstrated at the systems 


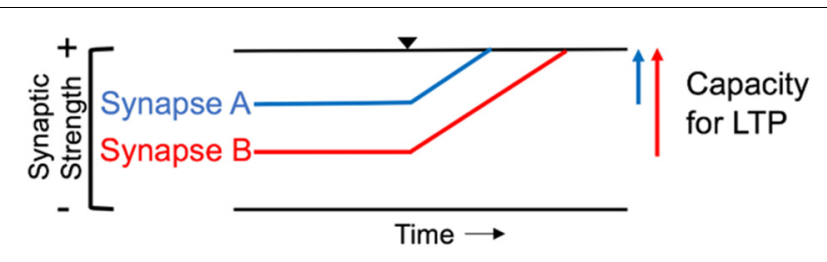

FIGURE 3 | Homeostatic range of synaptic modifiability. In the illustration, Synapse $A$ begins closer to its upper limit of modifiability (top black line) and has less capacity for long-term potentiation (LTP) than Synapse B. Black triangle denotes induction of LTP. Synapse $B$ is further from the upper limit of synaptic strength, resulting in a greater capacity for LTP induction compared to Synapse A.

level (Ziemann et al., 2004). It was shown that sensorimotor learning reduced the capacity for subsequent LTP but enhanced the capacity for LTD in human M1. Additionally, the degree to which further LTP is blocked has been correlated with the magnitude of motor memory retention after sensorimotor learning (Cantarero et al., 2013a,b). Taken together, these results highlight the importance of experience-dependent plasticity in sensorimotor learning. LTP is largely mediated by glutamate, the primary excitatory neurotransmitter in the brain, and its interaction with the $N$-methyl-D-aspartate (NMDA) receptor throughout the cortex (Lüscher and Malenka, 2012). Functional inactivation of the NMDA receptor in M1 abolished the capacity for LTP induction in vivo, suggesting that these glutamatergic receptors are necessary for LTP to occur (Hasan et al., 2013). In addition to glutamatergic synapse contributions to experience-dependent plasticity, gamma-aminobuytric acid (GABA) synaptic modifiability is another important contributor to plasticity. GABA is the main inhibitory neurotransmitter in the brain (Blicher et al., 2015), and transient reductions in GABAergic inhibition have been shown to be necessary for LTP induction in M1 (Hess et al., 1996; Blicher et al., 2015; Kida et al., 2016).

In subsequent sections, we will review the importance of sensory inputs in shaping experience-dependent plasticity underlying sensorimotor learning under normal conditions and after stroke.

\section{THE ROLE OF SENSORY REGIONS IN GOAL-DIRECTED HAND MOVEMENTS}

\section{Posterior Parietal Cortex (PPC) as a Sensorimotor Integration Hub}

The PPC is comprised of Brodmann Area (BA) 5, 7, 39 and 40 in the human brain and is anatomically connected to motor areas $\mathrm{M} 1$ and premotor cortex (PMC) via the superior longitudinal fasciculus (SLF; Makris et al., 2005; Koch et al., 2010). Although the PPC is not traditionally considered a primary part of the cortical motor network, it is involved in motor execution with populations of neurons that are motor dominant, in addition to populations that are visually dominant, or a combination of the two (Sakata et al., 1995). Non-human primate studies have demonstrated dense reciprocal PPC-M1 connections between the rostral strip of PPC and the medial lateral portion of M1
(Fang et al., 2005). Furthermore, regions of the PPC have distinct and direct pathways and networks with prefrontal motor cortical regions organized in functional zones (Gharbawie et al., 2011), which demonstrates the level of specific information the PPC can provide to the motor network. While PPC has been speculated to primarily influence M1 through polysynaptic connections with the PMC (Chao et al., 2015), support has been shown for monosynaptic projections from PPC to M1 (Karabanov et al., 2012). Additionally, in non-human primates, it has been shown that PPC has disynaptic connections with hand motoneurons in the dorsal horn and intermediate zone of the spinal cord (Rathelot et al., 2017), further suggesting potential contributions of PPC to the control of hand movements via the motor and sensory information PPC provides.

The PPC is a multisensory association area functioning to integrate different sensory modalities from visual, somatosensory, prefrontal and auditory inputs (Whitlock, 2017). The PPC has abundant reciprocal connections with sensory areas and is functionally parcellated such that the rostral portion of PPC is connected to somatosensory and motor regions, and the caudal portion of PPC has connections with visual and auditory regions (Stepniewska et al., 2009). The necessary inputs to PPC for sensorimotor processing needed for skilled hand movements include direct reciprocal inputs from the dorsomedial visual area that allows for continuous visual motion analysis necessary for interacting with the environment (Beck and Kaas, 1998; Kaskan and Kaas, 2007; Rosa et al., 2009; for review, see Kaas et al., 2011). Sensory inputs to BA 5 primarily come from somatosensory area S2 and the parietal ventral area, along with weaker inputs from S1 (Stepniewska et al., 2009). All three regions provide pertinent sensory information to PPC about proprioceptive and tactile activity of hand movements (Cohen et al., 1994; Prud'homme and Kalaska, 1994) that are important for sensorimotor integration used in hand exploration and object discrimination (Hinkley et al., 2007). Inputs to BA 5 are important as BA 5 is responsible for visuomotor transformations (Kalaska, 1996), making the PPC-M1 connection important for visuomotor control and visual-spatial processing (Binkofski et al., 1998; Mutha et al., 2011). PPC combines sensory signals about visual and kinematic reference frames into complex sensorimotor representations that are relayed to M1 to optimize motor commands (Sabes, 2011). PPC neurons are not only involved in control and error correction of a movement once initiated but are important for movement planning to achieve a motor goal (Mulliken et al., 2008; Aflalo et al., 2015), as neuronal firing also encodes movement intention (Snyder et al., 1997). Lesions in the rostral portion of PPC result in difficulty with shaping the fingers prior to grasping an object (Binkofski et al., 1998), further demonstrating an important role for PPC during the sensorimotor integration required for successfully performing goal-directed hand movements.

\section{Primary Somatosensory Cortex Involvement in Sensorimotor Integration}

In the human brain, $\mathrm{S} 1$ is comprised of $\mathrm{BA} 3 \mathrm{a}, 3 \mathrm{~b}, 1$, and 2 and receives direct somatosensory input from thalamus 
(Kaneko et al., 1994a). Somatosensory information is relayed from the periphery to the thalamus from the medial lemniscus (Boivie, 1978) via the spinothalamic tract (Boivie, 1979). Additionally, the posterior medial nucleus of the thalamus connects to inhibitory neurons in layer 1 (L1) of S1 that synapse onto the apical dendrites of neurons from other cortical layers (Castejon et al., 2016). Peripheral sensory information that is task-irrelevant can be filtered out through inhibition of afferent pathways via a process known as sensory gating (Eguibar et al., 1994). The thalamic relay nuclei are important for sensory gating, and lesions to the thalamus result in sensory gating impairments (Staines et al., 2002). This ascending sensory information can be modulated or gated by corticofugal descending projections from S1 to the dorsal column nuclei (Jabbur and Towe, 1961; Martinez-Lorenzana et al., 2001). Both S1 and M1 demonstrate somatotopic organization with representation of body regions localized to specific cortical cell columns (Kuehn et al., 2017). Furthermore, while M1 was previously thought to be agranular, it is now known that M1 shares the same structure as other primary cortical areas (Barbas and Garcia-Cabezas, 2015). The L4 in M1 is not cytoarchitecturally distinguishable, but electrophysiological studies have demonstrated it has traditional input/output proprieties: L4 receives excitatory input from the thalamus, has excitatory unidirectional outputs to $\mathrm{L} 2 / 3$, and weaker long-range corticortical connections (Yamawaki et al., 2014). However, there are distinct differences in that M1 has approximately half the amount of synapses that are exclusively excitatory whereas in $\mathrm{S} 1$, there are more synapses formed with both excitatory and inhibitory neurons (Bopp et al., 2017). It is proposed that M1 likely receives its feedforward inhibition through thalamacortical projections to L1 instead of L4 (Kuramoto et al., 2009; Bopp et al., 2017). In addition to connections from the thalamus, S1 also has direct projections to M1 that are important for the integration of somatosensory and motor information (Cash et al., 2015). In rodents, reciprocal projections connect the sensory representation in S1 to the corresponding motor representation in M1, creating a glutamatergic M1-S1 loop that connects $\mathrm{L} 2 / 3$ and $5 \mathrm{a}$ in S1 with L2/3 and 5a in M1 (Figure 4; Mao et al., 2011; Hooks et al., 2013). S1 relays somatosensory information through monosynaptic and polysynaptic connections to M1 (Kaneko et al., 1994a), and ongoing sensory input is used to refine and update descending motor commands (Rosenkranz and Rothwell, 2012). L2/3 neurons in M1 are able to directly excite pyramidal output neurons within the same cortical area (Kaneko et al., 1994b). At the network level, S1 activity has both excitatory (Rocco-Donovan et al., 2011) and inhibitory (Borich et al., 2015) effects on M1 at the network level. However, only excitatory projections from S1 to M1 have been characterized at the synaptic level (Papale and Hooks, 2018). The connectivity of inhibitory interneurons within M1 and how they are affected by sensory input have not been well studied. These S1-M1 connections provide an infrastructure for highly complex information integration that has the potential to be shaped and targeted for sensorimotor control and learning.

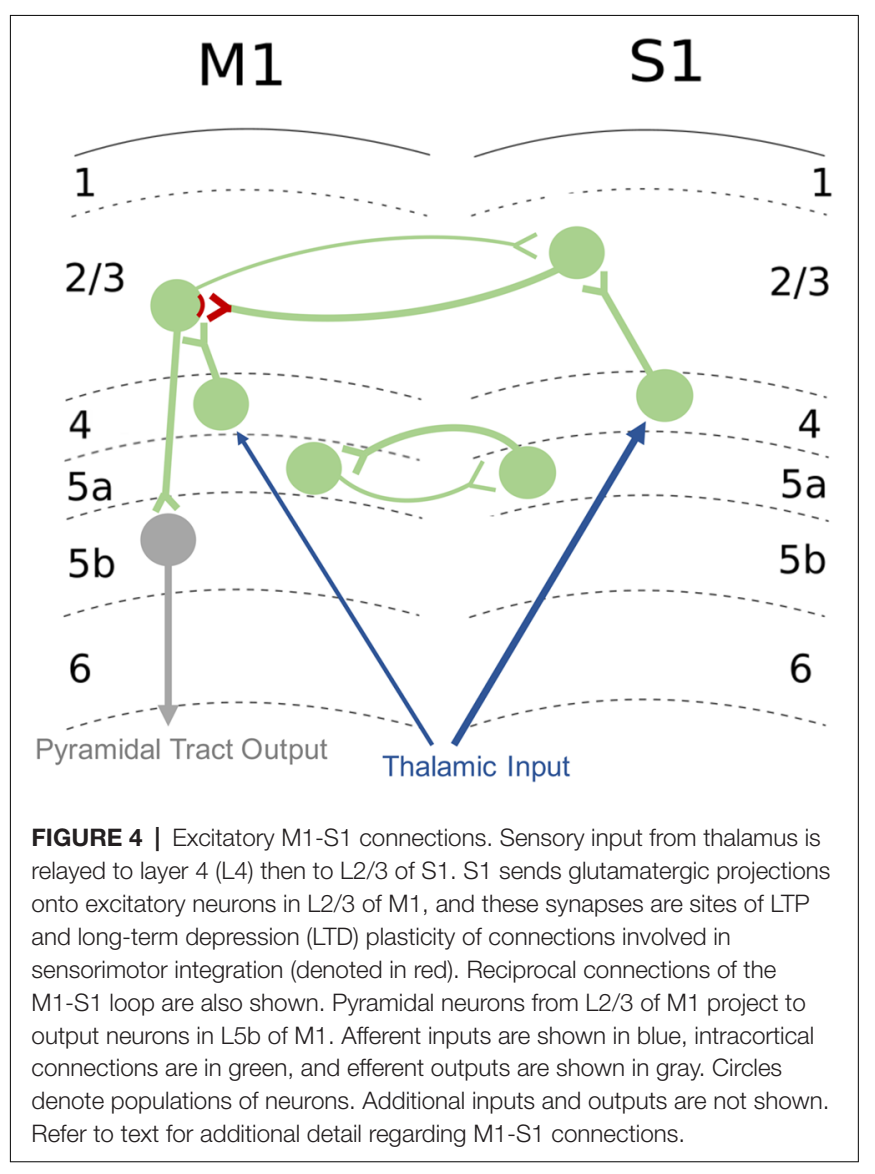

The ability of S1 to influence synaptic plasticity in M1 depends on sensorimotor synapses in L2/3 of M1. Synapses between S1 and M1 undergo plasticity that is driven by sensory input and results in the alteration of motor output (Kaneko et al., 1994a,b). These synapses are a main site of LTP and LTD in M1 (Kaneko et al., 1994a) and send excitatory projections to the pyramidal output neurons of M1 (Kaneko et al., 1994b; Huber et al., 2012). These connections allow for sensory feedback to shape motor output both in the short-term (immediate to minutes) and long-term (hours or longer). The ability for sensory input to influence motor output is specific to the connections between primary sensorimotor areas. Tetanic stimulation of S1, but not the ventrolateral nucleus of the thalamus, has been shown to produce LTP in L2/3 synapses of M1 (Iriki et al., 1989; Kaneko et al., 1994a). Tetanic stimulation of sensory thalamus only resulted in LTP in thalamocortical synapses with concurrent stimulation of S1 (Kaneko et al., 1994a). The S1-M1 connection has also been implicated in sensorimotor learning in vivo and is thought to be a main site of synaptic modifiability in response to motor skill learning (Papale and Hooks, 2018). These direct projections have been hypothesized to be a site of integration of sensory input and motor output and have an important role in guiding motor activity in response to sensory input (Hasan et al., 2013). One study in non-human primates demonstrated that ablation of S1 impaired the acquisition of motor skill but did not impair performance of the particular motor skill that had 
been learned previously, possibly due to intact thalamo-cortical connections that had been strengthened during skill training (Pavlides et al., 1993). Additionally, temporary inhibition of S1 in rodents has been shown to impair the ability to adapt motor performance based on changes in sensory input; however, basic motor patterns and motor commands that had learned previously were not affected (Mathis et al., 2017). Therefore, there is evidence to suggest that $\mathrm{S} 1$ is important for the ability to learn skilled movement and adjust motor plans to sensory input but may be less important for performance of overlearned or stereotyped movements in the upper limb. It should be noted, however, that ablation of other areas of S1, such as the face area, can lead to deficits in basic motor function, and previously learned motor tasks (Lin et al., 1993; Hiraba et al., 2000; Yao et al., 2002). In addition to connections between S1 and the ipsilateral M1, interhemispheric inhibitory connections between S1 s exist in humans (Ragert et al., 2011) and have been shown to influence plasticity in M1. For example, Conde et al. (2013) demonstrated that LTP-like plasticity in M1 induced by paired TMS and peripheral stimulation of the contralateral upper extremity switched to LTD-like plasticity when peripheral stimulation was applied to the upper limb ipsilateral to the TMS. These results demonstrate that the cortical sensorimotor circuitry that contributes to plasticity is not limited to one hemisphere, and interhemispheric network connectivity likely influences sensorimotor learning. However, the specific involvement of S1 in motor performance will depend on the characteristics of the task including the importance of sensory information for skilled performance.

\section{IMPACT OF STROKE ON SENSORIMOTOR INTEGRATION AND LEARNING}

\section{Sensorimotor Deficits After Stroke}

The impact of stroke on sensorimotor integration depends on the location of the stroke. Because the MCA supplies both the motor and sensory regions and is the most common type of stroke (Walcott et al., 2014), stroke in this vascular territory has a great likelihood of affecting sensorimotor integration. Therefore, our discussion is primarily focused on MCA strokes affecting the sensorimotor cortex although strokes in other vascular territories may also impact sensorimotor integration (Staines et al., 2002). There are dynamic processes post-stroke that change as a function of time and affect the neurophysiology of sensorimotor integration. Time post-stroke is defined in phases: hyper-acute ( $0-24 \mathrm{~h})$; acute (1-7 days); early subacute (7 days -3 months); late subacute (3-6 months); and chronic (>6 months; Bernhardt et al., 2017b). Initial neuronal cell death in the lesion core leads to both structural and functional disconnection with brain regions outside the primary area of infarct (Carrera and Tononi, 2014). Motor recovery occurs in part from spontaneous biological repair (SBR) that transitions from a state of cell death and inflammation to a state of increased neuronal excitability and experiencedependent plasticity lasting $\sim 3$ months post-stroke (Cramer, 2008). Most recovery post-stroke occurs rapidly in the early sub-acute phase and the magnitude of improvement slows down in the late sub-acute phase (Lee et al., 2015). In the chronic phase post-stroke, patients have reached a stable, though modifiable plateau in motor recovery (Jørgensen et al., 1995) with less than $20 \%$ of patients experiencing full recovery of upper extremity motor function (Kwakkel et al., 2003).

Upper extremity paresis is the most predominant motor impairment after MCA stroke, which results from a lesion involving the CST that is also necessary for skilled hand movements (Lang and Schieber, 2003). Paresis can contribute to deficits in both the initiation and termination of voluntary movement of the wrist (Chae et al., 2002). Other motor deficits include spasticity and impaired motor control (Raghavan, 2015), with $85 \%$ of patients in the chronic phase post-stroke still possessing residual motor deficits (Lee et al., 2015).

Common somatosensory modalities affected after stroke are tactile sensation, proprioception, and stereognosis (Connell et al., 2008). It has been recently reported that $62 \%$ of acute stroke patients demonstrated deficits in their ability to locate their hand and arm in space (Findlater et al., 2016). Deficits in proprioception have direct implications as information about the arm and hand are necessary for proper movement and important for improving sensorimotor function after stroke (Aman et al., 2014). Due to the reliance of the motor system on sensory information for movement optimization, sensory impairment is expected to have motor repercussions. Similarly, sensory deficits can occur even when there are ischemic lesions specifically in the M1 motor pathway and not in somatosensory afferents (Nudo et al., 2000), suggesting that sensory integration can be disrupted even in the absence of a lesion present in sensory afferent pathways. Clinically, sensorimotor deficits are usually discussed in terms of sensory deficits and motor deficits assessed separately. Sensory and/or motor deficits after stroke have been routinely measured using observer-based clinical scales either focused on measuring level of impairment, with scales such as the Fugl-Meyer Assessment (Fugl-Meyer et al., 1975) and Nottingham Sensory Assessment (Lincoln et al., 1998), or focused on measuring level of function with the Wolf Motor Function Test (Wolf et al., 2001) and the Jebsen Taylor Hand Test (Jebsen et al., 1969). However, there are several limitations of standard observer-based clinical assessments including: decreased reliability and sensitivity compared to objective assessments, lack of precision with non-continuous data, and greater susceptibility to floor and ceiling effects of performance (Scott and Dukelow, 2011). Therefore, there is a need for objective assessments to better characterize post-stroke sensorimotor deficits.

\section{Assessment of Sensorimotor Integration After Stroke}

In addition to the need for objective assessments of sensorimotor deficits, it is important to examine the impact of stroke on sensorimotor integration to better understand the relationship between sensory and motor deficits. As defined earlier, sensorimotor integration is the ability to incorporate sensory inputs to shape motor output (Wolpert et al., 1998). Therefore, examining the effects of manipulating sensory information on motor output can be employed to evaluate 
sensorimotor integration. For a detailed review of various measurement techniques, see Riemann et al. (2002). One approach utilizes robotic-based technologies during visually guided upper extremity tasks to quantify aspects of sensorimotor control. Coderre et al. (2010) examined the characteristics of feed-forward control and feedback control of stroke patients in the early sub-acute recovery period. It was observed that most patients with deficits initiating movement also had deficits with adjusting movement from sensory feedback, emphasizing that movement difficulties were not solely due to motor impairments but also due to an inefficiency with integration of sensory modalities. Using another robotic-based assessment, it was shown that kinesthetic impairments post-stroke were not resolved with the addition of visual information indicating the location of the arm in space (Semrau et al., 2018). This observation was unique to stroke patients in comparison to healthy controls and the impairment was attributed, in part, to damage to the PPC. Studies have previously shown that sensorimotor abnormalities during motor control are related to parietal lesions (Desmurget et al., 1999; Findlater et al., 2016), signifying the important role of PPC in sensorimotor integration.

In addition to robotic-based assessments, sensorimotor integration has also been probed using non-invasive stimulation in humans. Combining a peripheral sensory stimulus with non-invasive brain stimulation using TMS can measure the effects of afferent sensory input on the magnitude of TMS-evoked motor output. One example assessment is short-latency afferent inhibition (SAI) where somatosensory input from peripheral stimulation of the median nerve can inhibit motor output to hand muscles (Tokimura et al., 2000). In the acute phase post-stroke, patients have reduced SAI compared to healthy controls (Di Lazzaro et al., 2012), that seems to normalize in the chronic phase where there is no significant difference in SAI between patients and controls (Brown et al., 2018). Sensorimotor integration may be disrupted shortly after stroke but this reduction was correlated with improved outcome in the chronic phase (Di Lazzaro et al., 2012) This suggests that while decreased SAI may be beneficial acutely, it must normalize chronically for improved motor function. Previous work has also shown that the integration of S1 afferent input to M1 decreased acutely but was more comparable to healthy controls at 6 months poststroke; this finding also paralleled improvement in sensation (Bannister et al., 2015). Sensorimotor integration has also been assessed using a vibration-based sensory stimulus of the muscle belly preceding TMS. It was found sensorimotor integration was abnormal in chronic stroke patients and greater abnormality was associated with greater magnitude of motor impairment and dysfunction (Brown et al., 2018). Taken together, these studies demonstrate that sensorimotor integration is impacted differentially depending on time post-stroke and the type of sensory information provided, but overall is an important process during recovery.

\section{Plasticity and Sensorimotor Learning After Stroke}

Many cellular and synaptic processes contribute to plasticity after stroke. In the acute phase after stroke, LTP is facilitated in the perilesional areas, suggesting an amplification of network plasticity that influences cortical reorganization (Hagemann et al., 1998). Neuroplasticity is enhanced through processes such as axonal sprouting and GABA receptor downregulation (Carmichael, 2016). Additionally, functional recovery is most rapid during this early time period, occurring in the first 3 months for humans and roughly 1 month for rodents (Caleo, 2015). Plasticity subsequently plateaus in the chronic stage of recovery (Hendricks et al., 2002; Hara, 2015). Rehabilitative interventions have been shown to be most effective when initiated early after stroke and become less effective with time post-stroke (Biernaskie et al., 2004). Despite the plateau in neuroplasticity during the chronic phase of recovery, it is currently unclear whether this level differs from that of matched healthy controls. In a study by Zeiler et al. (2016) in a rodent model of chronic stroke, the induction of a second stroke enhanced plasticity and response to skilled motor training, indicating that it is possible to reopen this window of enhanced plasticity during the later stages of recovery. Increasing the capacity for neuroplasticity during the chronic stage of recovery has the potential to enhance recovery of function for stroke survivors with persistent motor-related disability.

As mentioned previously, GABAergic activity is strongly related to synaptic plasticity in healthy individuals. In rodent models of cerebral ischemia, GABAergic inhibition has been shown to be elevated within minutes (Globus et al., 1991), a potentially neuroprotective mechanism to counteract excitotoxicity caused by excess glutamate release (PellegriniGiampietro, 2003). GABA levels return to baseline within an hour of reoxygenation (Schwartz-Bloom and Sah, 2001). Reductions in GABAergic inhibition continue during the acute phase after stroke, and this process has been related to functional motor recovery in mice (Clarkson et al., 2010). It has been suggested that this reduction in GABAergic activity serves to facilitate neuroplasticity in M1 through unmasking of existing, inactive synaptic connections (Paik and Yang, 2014), the development of new connections (Murphy and Corbett, 2009), or the induction of LTP (Hess et al., 1996; Sanes and Donoghue, 2000). While GABAergic activity has been shown to be an important contributor to plasticity after stroke, other mechanisms, such as brain derived neurotrophic factor (BDNF) and neuromodulin signaling, have been implicated as well. For in-depth reviews of cellular and synaptic mechanisms of plasticity after stroke, see Murphy and Corbett (2009) and Alia et al. (2017). Given that similar mechanisms are thought to underlie neuroplasticity and functional recovery after stroke (Kleim and Jones, 2008), therapeutic strategies that optimally promote neuroplasticity hold promise for improving the rate and magnitude of functional recovery after stroke.

As discussed earlier, motor skill learning has been shown to induce structural and functional changes in M1 that underpin sensorimotor learning in rodents (Kleim et al., 1998), non-human primates (Nudo, 2013), and healthy humans (Bütefisch et al., 2000; Sanes and Donoghue, 2000; Ziemann et al., 2004). It has also been shown that motor skill learning underlies recovery of function after stroke in humans (Krakauer, 2006) and non-human primates (Nudo et al., 1996b). One mechanism 
underlying recovery is the preservation or expansion of the M1 representation of the affected hand. Skilled motor training after stroke in non-human primates prevented the reduction of the affected distal upper extremity representation in M1 that occurred after an equivalent period of no training (Nudo et al., 1996b). In some cases, the hand representation expanded into representations for adjacent body parts after training, and this reorganization of $\mathrm{M} 1$ corresponded to better recovery of skilled hand function. It has also been shown that $\mathrm{S} 1$ activity contributes to sensorimotor learning and recovery after stroke in humans and non-human primates. Nudo et al. (2000) demonstrated that impairments in sensory inputs to M1 after stroke in non-human primates contributed to motor deficits in a task that required skilled hand movements. In humans, continuous theta burst stimulation (cTBS), a TMS paradigm that can decrease excitability of the stimulated area, delivered over contralesional $\mathrm{S} 1$ in order to reduce transcallosal inhibition on ipsilesional S1 was shown to enhance motor recovery after stroke (Meehan et al., 2011). Another study by Brodie et al. (2014) demonstrated that excitatory rTMS to the ipsilesional S1 paired with motor skill training increased sensorimotor learning compared to stimulation or skill training in isolation. Therefore, attempting to enhance S1 excitability and/or sensorimotor integration may offer an effective approach to improve sensorimotor learning and functional recovery after stroke.

\section{STRATEGIES TO MODULATE SENSORIMOTOR INTEGRATION AND POTENTIAL THERAPEUTIC EFFECTS AFTER STROKE}

\section{Current Therapeutic Interventions}

Sensorimotor integration occurs across the neuraxis and therefore provides multiple potential targets for therapeutic intervention. Several experimental procedures have been developed to modulate afferent input to $\mathrm{M} 1$, and therefore sensorimotor integration, in humans. Peripheral vibration is a neuromodulation approach that increases afferent input that is thought to modulate M1 excitability by regulating the activity of cortical inhibitory interneurons that are involved in motor output (Rosenkranz and Rothwell, 2006). This increase in afferent input is thought to change the response of M1 to sensory input and therefore influence sensorimotor integration in the cortex. Both focal (Celletti et al., 2017) and whole-body vibration (Boo et al., 2016) have shown promise in improving upper extremity function in individuals with stroke. However, across studies, the effectiveness of vibration to improve post-stroke motor function remains unclear (Liao et al., 2014; Park et al., 2018).

In contrast to increasing afferent input to M1, models of temporary deafferentation have shown promise in targeting sensorimotor integration by reducing sensory input to modulate motor output. In rodents, transection of the facial nerve leads to a rapid expansion of the adjacent forelimb representation in M1, likely due to rapid removal of GABAergic inhibition (Sanes et al., 1988; Huntley, 1997). This concept has been applied non-invasively in humans by temporarily reducing afferent input from a portion of the upper extremity to M1 with the goal of reducing GABAergic inhibition to adjacent areas of the limb. It is thought that rapid unmasking of horizontal connections leads to an expansion of the cortical representation. Targeting this mechanism, several temporary deafferentation strategies have been studied in humans with the goal of increasing M1 representation of the affected limb to improve functional outcomes after stroke. Ischemic nerve block (INB) of the arm is one method that serves as a model of transient segmental deafferentation in humans. Using a pneumatic tourniquet at the elbow, afferent sensory inputs from the distal forearm to the sensorimotor cortex are restricted, leading to an increase in excitability of cortical representations of muscles immediately proximal to the deafferented forearm (Brasil-Neto et al., 1993). However, this form of INB may be less applicable for individuals with stroke, as a main goal of stroke rehabilitation is to improve hand function, and it appears that INB effects more proximal parts of the arm (Lang et al., 2013). A different approach that has been shown to increase motor function after stroke is the application of anesthesia to areas proximal to the hand, such as the brachial plexus (Muellbacher et al., 2002a) or forearm (Sens et al., 2012, 2013), simulating deafferentation of the upper or lower arm, respectively. After applying anesthesia to the brachial plexus of the affected arm, Muellbacher et al. (2002a) demonstrated an improvement in motor skill after training in individuals with chronic stroke compared to training without anesthesia. Additionally, there was an increase in motor output in response to TMS application with no change in motor threshold, suggesting a rapid cortical reorganization and reduction in inhibition. Application of anesthetic cream to the forearm, another region proximal to the hand, improved somatosensory and motor function distal to the site of application in individuals with chronic stroke (Sens et al., 2013). Blood flow restriction (BFR) is another technique that uses a pneumatic cuff applied to the arm to reduce blood flow to a target level that is maintained during exercise (Yasuda et al., 2014). Brandner et al. (2015) showed that BFR during resistance exercise increases corticomotor excitability, and this effect is thought to be mediated by the reduction in cortical afferent input. A primary concern for the use of INB and BFR in a rehabilitation setting is that the use of a tourniquet or arm cuff poses a risk for individuals with sensory impairments and/or cardiovascular irregularities, such as individuals with stroke (Spranger et al., 2015). Therefore, individuals with stroke may benefit from a method of temporary deafferentation with fewer potential risks.

\section{Future Directions for Therapeutic Interventions}

Short-term immobilization of the arm is a safe, low-cost approach for the transient modulation of sensorimotor cortical function in healthy individuals. In humans and animals, prolonged immobilization or disuse of a limb can occur after neurological insult that induces maladaptive plasticity, such as reduction in cortical representations of the limb (Pons et al., 1991; Langer et al., 2012; Milliken et al., 2013; Viaro et al., 2014), which can contribute to "learned nonuse" and a compensatory 
reliance on the unaffected limb (Wolf, 2007). While learned nonuse and its effects on cortical organization have been examined, short-term immobilization has been less well-studied. Short-term arm immobilization (typically $8 \mathrm{~h}$ ) reduces sensory input to, and motor output from, the contralateral sensorimotor cortex resulting in transiently decreased M1 and S1 cortical excitability following immobilization in healthy individuals (Huber et al., 2006; Rosenkranz et al., 2014). This decrease in excitability is thought to be driven by LTD-like processes (Huber et al., 2006). Allen et al. (2003) demonstrated that whisker deprivation in rodents induced LTD-like effects in sensorimotor areas that occluded further LTD induction but enhanced LTP induction in slice preparations, consistent with the model of homeostatic metaplasticity. Short-term immobilization of the arm has been proposed as a strategy to induce LTD-like plasticity and enhance the capacity for LTP induction in the human motor cortex. Indeed, a single short bout $(8 \mathrm{~h})$ of immobilization temporarily reduced TMS-based measures of cortical excitability; however, the capacity for synaptic strengthening was significantly enhanced (Rosenkranz et al., 2014). However, the behavioral effects of this enhanced synaptic strengthening are currently unclear.

Given that short-term immobilization modulates excitability of S1 and M1, it is likely that immobilization impacts the integration of sensory and motor information that underlies experience-dependent plasticity. Therefore, short-term immobilization could potentially modulate neural processes underlying sensorimotor learning. However, the effects of immobilization on sensorimotor learning have not been well studied in humans. To our knowledge, only one study has examined sensorimotor learning after short-term arm immobilization (Opie et al., 2016) and did not show a clear effect of immobilization on sensorimotor learning. The lack of effect could be due, in part, to the high number of individuals with the BDNF Val66Met polymorphism that is associated with reduced use-dependent plasticity in sensorimotor areas (Kleim et al., 2006). Given the relationship between neural plasticity and sensorimotor learning, further examination of the effect of short-term arm immobilization on sensorimotor learning is warranted. Short-term arm immobilization could show promise as a rehabilitative intervention to increase post-stroke sensorimotor recovery by enhancing the capacity

\section{REFERENCES}

Abraham, W. C., and Bear, M. F. (1996). Metaplasticity: the plasticity of synaptic plasticity. Trends Neurosci. 19, 126-130. doi: 10.1016/s0166-2236(96)80018-x

Aflalo, T., Kellis, S., Klaes, C., Lee, B., Shi, Y., Pejsa, K., et al. (2015). Neurophysiology. Decoding motor imagery from the posterior parietal cortex of a tetraplegic human. Science 348, 906-910. doi: 10.1126/science. aaa5417

Alia, C., Spalletti, C., Lai, S., Panarese, A., Lamola, G., Bertolucci, F., et al. (2017). Neuroplastic changes following brain ischemia and their contribution to stroke recovery: novel approaches in neurorehabilitation. Front. Cell. Neurosci. 11:76. doi: 10.3389/fncel.2017.00076

Allen, C. B., Celikel, T., and Feldman, D. E. (2003). Long-term depression induced by sensory deprivation during cortical map plasticity in vivo. Nat. Neurosci. 6, 291-299. doi: $10.1038 / \mathrm{nn} 1012$ for neuroplasticity leading to better training-related increases in motor function. More broadly, given its demonstrated role in motor control, promotion of sensorimotor integration plasticity has potential as a therapeutic strategy post-stroke.

\section{CONCLUSION}

Skilled hand movements are necessary for normal function in daily life but are frequently impaired after stroke. Goal-directed functional movements rely on accurate integration sensory information and when sensorimotor integration is compromised, movement ability is compromised. Despite the importance of sensory contributions to normal and abnormal movement, research has predominantly focused on motor aspects of stroke recovery. Given that sensorimotor integration has been shown to be negatively impacted after stroke and correlated with level of recovery, there is an increasing need to focus future research efforts towards comprehensive characterization of the neural mechanisms of sensorimotor integration and their contributions to functional movements in both health and disease. Furthermore, an increased understanding of contributions of sensorimotor integration and sensorimotor learning to skilled hand movements post-stroke will likely offer new rehabilitative targets to increase the recovery of function after stroke.

\section{AUTHOR CONTRIBUTIONS}

LE and EK planned, drafted, and edited the manuscript. CB and $\mathrm{MB}$ planned and edited the manuscript.

\section{FUNDING}

The authors would like to acknowledge their funding sources. LE is supported by R01NS090677-04S1. EK is supported by 2T32HD071845-06. CB is partially supported by R01NS090677, R21NS092385, StrokeNet U24NS107234. MB is supported by NIH NCMRR, K12HD055931, P2CCHD086844 and a Research Grant from the Foundation for Physical Therapy. The funding for open access publication fee for this article were provided by the Emory University Department of Rehabilitation Medicine.

Aman, J. E., Elangovan, N., Yeh, I. L., and Konczak, J. (2014). The effectiveness of proprioceptive training for improving motor function: a systematic review. Front. Hum. Neurosci. 8:1075. doi: 10.3389/fnhum.2014. 01075

Arce-McShane, F. I., Hatsopoulos, N. G., Lee, J. C., Ross, C. F., and Sessle, B. J. (2014). Modulation dynamics in the orofacial sensorimotor cortex during motor skill acquisition. J. Neurosci. 34, 5985-5997. doi: 10.1523/jneurosci.436713.2014

Arima, T., Yanagi, Y., Niddam, D. M., Ohata, N., Arendt-Nielsen, L., Minagi, S., et al. (2011). Corticomotor plasticity induced by tongue-task training in humans: a longitudinal fMRI study. Exp. Brain Res. 212, 199-212. doi: 10.1007/s00221-011-2719-7

Baker, S. N. (2011). The primate reticulospinal tract, hand function and functional recovery. J. Physiol. 589, 5603-5612. doi: 10.1113/jphysiol.2011. 215160 
Bannister, L. C., Crewther, S. G., Gavrilescu, M., and Carey, L. M. (2015). Improvement in touch sensation after stroke is associated with resting functional connectivity changes. Front. Neurol. 6:165. doi: 10.3389/fneur.2015. 00165

Barbas, H., and Garcia-Cabezas, M. A. (2015). Motor cortex layer 4: less is more. Trends Neurosci. 38, 259-261. doi: 10.1016/j.tins.2015.03.005

Beck, P. D., and Kaas, J. H. (1998). Cortical connections of the dorsomedial visual area in prosimian primates. J. Comp. Neurol. 398, 162-178. doi: 10.1002/(sici)1096-9861(19980824)398:2<162::aid-cne2>3.0.co;2-z

Benjamin, E. J., Blaha, M. J., Chiuve, S. E., Cushman, M., Das, S. R., Deo, R., et al. (2017). Heart disease and stroke statistics-2017 update: a report from the american heart association. Circulation 135, e146-e603. doi: 10.1161/CIR. 0000000000000485

Bernhardt, J., Godecke, E., Johnson, L., and Langhorne, P. (2017a). Early rehabilitation after stroke. Curr. Opin. Neurol. 30, 48-54. doi: 10.1097/WCO. 0000000000000404

Bernhardt, J., Hayward, K. S., Kwakkel, G., Ward, N. S., Wolf, S. L., Borschmann, K., et al. (2017b). Agreed definitions and a shared vision for new standards in stroke recovery research: the stroke recovery and rehabilitation roundtable taskforce. Neurorehabil. Neural Repair 31, 793-799. doi: $10.1177 / 1545968317732668$

Biernaskie, J., Chernenko, G., and Corbett, D. (2004). Efficacy of rehabilitative experience declines with time after focal ischemic brain injury. J. Neurosci. 24, 1245-1254. doi: 10.1523/JNEUROSCI.3834-03.2004

Binkofski, F., Dohle, C., Posse, S., Stephan, K. M., Hefter, H., Seitz, R. J., et al. (1998). Human anterior intraparietal area subserves prehension: a combined lesion and functional MRI activation study. Neurology 50, 1253-1259. doi: $10.1212 /$ wnl.50.5.1253

Blakemore, S. J., Goodbody, S. J., and Wolpert, D. M. (1998). Predicting the consequences of our own actions: the role of sensorimotor context estimation. J. Neurosci. 18, 7511-7518. doi: 10.1523/jneurosci.18-18-07511.1998

Blicher, J. U., Near, J., Naess-Schmidt, E., Stagg, C. J., Johansen-Berg, H., Nielsen, J. F., et al. (2015). GABA levels are decreased after stroke and GABA changes during rehabilitation correlate with motor improvement. Neurorehabil. Neural Repair 29, 278-286. doi: 10.1177/1545968314543652

Boivie, J. (1978). Anatomical observations on the dorsal column nuclei, their thalamic projection and the cytoarchitecture of some somatosensory thalamic nuclei in the monkey. J. Comp. Neurol. 178, 17-48. doi: 10.1002/cne.901780103

Boivie, J. (1979). An anatomical reinvestigation of the termination of the spinothalamic tract in the monkey. J. Comp. Neurol. 186, 343-369. doi: $10.1002 / \mathrm{cne} .901860304$

Bolognini, N., Russo, C., and Edwards, D. J. (2016). The sensory side of post-stroke motor rehabilitation. Restor. Neurol. Neurosci. 34, 571-586. doi: 10.3233/rnn150606

Boo, J. A., Moon, S. H., Lee, S. M., Choi, J. H., and Park, S. E. (2016). Effect of whole-body vibration exercise in a sitting position prior to therapy on muscle tone and upper extremity function in stroke patients. J. Phys. Ther. Sci. 28, 558-562. doi: $10.1589 /$ jpts.28.558

Bopp, R., Holler-Rickauer, S., Martin, K. A., and Schuhknecht, G. F. (2017). An ultrastructural study of the thalamic input to layer 4 of primary motor and primary somatosensory cortex in the mouse. J. Neurosci. 37, 2435-2448. doi: 10.1523/jneurosci.2557-16.2017

Borich, M. R., Brodie, S. M., Gray, W. A., Ionta, S., and Boyd, L. A. (2015). Understanding the role of the primary somatosensory cortex: opportunities for rehabilitation. Neuropsychologia 79, 246-255. doi: 10.1016/j.neuropsychologia. 2015.07.007

Bosch-Bouju, C., Hyland, B. I., and Parr-Brownlie, L. C. (2013). Motor thalamus integration of cortical, cerebellar and basal ganglia information: implications for normal and parkinsonian conditions. Front. Comput. Neurosci. 7:163. doi: $10.3389 /$ fncom. 2013.00163

Brandner, C. R., Warmington, S. A., and Kidgell, D. J. (2015). Corticomotor excitability is increased following an acute bout of blood flow restriction resistance exercise. Front. Hum. Neurosci. 9:652. doi: 10.3389/fnhum.2015. 00652

Brasil-Neto, J. P., Valls-Solé, J., Pascual-Leone, A., Cammarota, A., Amassian, V. E., Cracco, R., et al. (1993). Rapid modulation of human cortical motor outputs following ischaemic nerve block. Brain 116, 511-525. doi: 10.1093/brain/116.3.511
Brodie, S. M., Meehan, S., Borich, M. R., and Boyd, L. A. (2014). 5 Hz repetitive transcranial magnetic stimulation over the ipsilesional sensory cortex enhances motor learning after stroke. Front. Hum. Neurosci. 8:143. doi: 10.3389/fnhum. 2014.00143

Brown, K. E., Neva, J. L., Feldman, S. J., Staines, W. R., and Boyd, L. A. (2018). Sensorimotor integration in chronic stroke: baseline differences and response to sensory training. Restor. Neurol. Neurosci. 36, 245-259. doi: 10.3233/RNN170790

Burnod, Y., Grandguillaume, P., Otto, I., Ferraina, S., Johnson, P. B., and Caminiti, R. (1992). Visuomotor transformations underlying arm movements toward visual targets: a neural network model of cerebral cortical operations. J. Neurosci. 12, 1435-1453. doi: 10.1523/jneurosci.12-04-01435.1992

Bütefisch, C. M., Davis, B. C., Wise, S. P., Sawaki, L., Kopylev, L., Classen, J., et al. (2000). Mechanisms of use-dependent plasticity in the human motor cortex. Proc. Natl. Acad. Sci. U S A 97, 3661-3665. doi: 10.1073/pnas. 050350297

Caleo, M. (2015). Rehabilitation and plasticity following stroke: insights from rodent models. Neuroscience 311, 180-194. doi: 10.1016/j.neuroscience.2015. 10.029

Cantarero, G., Lloyd, A., and Celnik, P. (2013a). Reversal of long-term potentiation-like plasticity processes after motor learning disrupts skill retention. J. Neurosci. 33, 12862-12869. doi: 10.1523/jneurosci.1399-13.2013

Cantarero, G., Tang, B., O’Malley, R., Salas, R., and Celnik, P. (2013b). Motor learning interference is proportional to occlusion of LTP-like plasticity. J. Neurosci. 33, 4634-4641. doi: 10.1523/jneurosci.4706-12.2013

Carmichael, S. T. (2016). The 3 Rs of stroke biology: radial, relayed and regenerative. Neurotherapeutics 13, 348-359. doi: 10.1007/s13311-015-0408-0

Carrera, E., and Tononi, G. (2014). Diaschisis: past, present, future. Brain 137, 2408-2422. doi: 10.1093/brain/awu101

Cash, R. F., Isayama, R., Gunraj, C. A., Ni, Z., and Chen, R. (2015). The influence of sensory afferent input on local motor cortical excitatory circuitry in humans. J. Physiol. 593, 1667-1684. doi: 10.1113/jphysiol.2014.286245

Castejon, C., Barros-Zulaica, N., and Nunez, A. (2016). Control of somatosensory cortical processing by thalamic posterior medial nucleus: a new role of thalamus in cortical function. PLoS One 11:e0148169. doi: 10.1371/journal.pone.0148169

Celletti, C., Sinibaldi, E., Pierelli, F., Monari, G., and Camerota, F. (2017) Focal muscle vibration and progressive modular rebalancing with neurokinetic facilitations in post- stroke recovery of upper limb. Clin. Ter. 168, e33-e36. doi: 10.7417/CT.2017.1979

Chae, J., Yang, G., Park, B. K., and Labatia, I. (2002). Delay in initiation and termination of muscle contraction, motor impairment and physical disability in upper limb hemiparesis. Muscle Nerve 25, 568-575. doi: 10.1002/mus.10061

Chao, C. C., Karabanov, A. N., Paine, R., Carolina De Campos, A., Kukke, S. N., $\mathrm{Wu}, \mathrm{T}$., et al. (2015). Induction of motor associative plasticity in the posterior parietal cortex-primary motor network. Cereb. Cortex 25, 365-373. doi: 10.1093/cercor/bht230

Clarkson, A. N., Huang, B. S., Macisaac, S. E., Mody, I., and Carmichael, S. T. (2010). Reducing excessive GABA-mediated tonic inhibition promotes functional recovery after stroke. Nature 468, 305-309. doi: 10.1038/nature09511

Coderre, A. M., Zeid, A. A., Dukelow, S. P., Demmer, M. J., Moore, K. D., Demers, M. J., et al. (2010). Assessment of upper-limb sensorimotor function of subacute stroke patients using visually guided reaching. Neurorehabil. Neural Repair 24, 528-541. doi: 10.1177/1545968309356091

Cohen, D. A., Prud'homme, M. J., and Kalaska, J. F. (1994). Tactile activity in primate primary somatosensory cortex during active arm movements: correlation with receptive field properties. J. Neurophysiol. 71, 161-172. doi: 10.1152/jn.1994.71.1.161

Conde, V., Vollmann, H., Taubert, M., Sehm, B., Cohen, L. G., Villringer, A., et al. (2013). Reversed timing-dependent associative plasticity in the human brain through interhemispheric interactions. J. Neurophysiol. 109, 2260-2271. doi: 10.1152/jn.01004.2012

Connell, L. A., Lincoln, N. B., and Radford, K. A. (2008). Somatosensory impairment after stroke: frequency of different deficits and their recovery. Clin. Rehabil. 22, 758-767. doi: 10.1177/0269215508090674

Cramer, S. C. (2008). Repairing the human brain after stroke: I. Mechanisms of spontaneous recovery. Ann. Neurol. 63, 272-287. doi: 10.1002/ana. 21393 
Desmurget, M., Epstein, C. M., Turner, R. S., Prablanc, C., Alexander, G. E., and Grafton, S. T. (1999). Role of the posterior parietal cortex in updating reaching movements to a visual target. Nat. Neurosci. 2, 563-567. doi: 10.1038/9219

Di Lazzaro, V., Profice, P., Pilato, F., Capone, F., Ranieri, F., Florio, L., et al. (2012). The level of cortical afferent inhibition in acute stroke correlates with long-term functional recovery in humans. Stroke 43, 250-252. doi: 10.1161/STROKEAHA.111.631085

Dum, R. P., and Strick, P. L. (1996). Spinal cord terminations of the medial wall motor areas in macaque monkeys. J. Neurosci. 16, 6513-6525. doi: 10.1523/jneurosci.16-20-06513.1996

Eguibar, J. R., Quevedo, J., Jiménez, I., and Rudomin, P. (1994). Selective cortical control of information flow through different intraspinal collaterals of the same muscle afferent fiber. Brain Res. 643, 328-333. doi: 10.1016/00068993(94)90042-6

Fang, P. C., Stepniewska, I., and Kaas, J. H. (2005). Ipsilateral cortical connections of motor, premotor, frontal eye and posterior parietal fields in a prosimian primate, Otolemur garnetti. J. Comp. Neurol. 490, 305-333. doi: 10.1002/cne. 20665

Findlater, S. E., Desai, J. A., Semrau, J. A., Kenzie, J. M., Rorden, C., Herter, T. M., et al. (2016). Central perception of position sense involves a distributed neural network - evidence from lesion-behavior analyses. Cortex 79, 42-56. doi: 10.1016/j.cortex.2016.03.008

Flanagan, J. R., Bowman, M. C., and Johansson, R. S. (2006). Control strategies in object manipulation tasks. Curr. Opin. Neurobiol. 16, 650-659. doi: 10.1016/j. conb.2006.10.005

Friel, K. M., Barbay, S., Frost, S. B., Plautz, E. J., Hutchinson, D. M., Stowe, A. M., et al. (2005). Dissociation of sensorimotor deficits after rostral versus caudal lesions in the primary motor cortex hand representation. J. Neurophysiol. 94, 1312-1324. doi: 10.1152/jn.01251.2004

Fugl-Meyer, A. R., Jääskö, L., Leyman, I., Olsson, S., and Steglind, S. (1975). The post-stroke hemiplegic patient. 1. A method for evaluation of physical performance. Scand. J. Rehabil. Med. 7, 13-31.

Georgopoulos, A. P., Ashe, J., Smyrnis, N., and Taira, M. (1992). The motor cortex and the coding of force. Science 256, 1692-1695. doi: 10.1126/science.256. 5064.1692

Georgopoulos, A. P., Kalaska, J. F., Caminiti, R., and Massey, J. T. (1982). On the relations between the direction of two-dimensional arm movements and cell discharge in primate motor cortex. J. Neurosci. 2, 1527-1537. doi: 10.1523/jneurosci.02-11-01527.1982

Gharbawie, O. A., Stepniewska, I., and Kaas, J. H. (2011). Cortical connections of functional zones in posterior parietal cortex and frontal cortex motor regions in new world monkeys. Cereb. Cortex 21, 1981-2002. doi: 10.1093/cercor/ bhq260

Globus, M. Y., Busto, R., Martinez, E., Valdes, I., Dietrich, W. D., and Ginsberg, M. D. (1991). Comparative effect of transient global ischemia on extracellular levels of glutamate, glycine and $\gamma$-aminobutyric acid in vulnerable and nonvulnerable brain regions in the rat. J. Neurochem. 57, 470-478. doi: 10.1111/j.1471-4159.1991.tb03775.x

Griffin, D. M., Hoffman, D. S., and Strick, P. L. (2015). Corticomotoneuronal cells are "functionally tuned". Science 350, 667-670. doi: 10.1126/science. aaa8035

Hagemann, G., Redecker, C., Neumann-Haefelin, T., Freund, H. J., and Witte, O. W. (1998). Increased long-term potentiation in the surround of experimentally induced focal cortical infarction. Ann. Neurol. 44, 255-258. doi: 10.1002/ana.410440217

Hara, Y. (2015). Brain plasticity and rehabilitation in stroke patients. J. Nippon Med. Sch. 82, 4-13. doi: 10.1272/jnms.82.4

Hasan, M. T., Hernández-González, S., Dogbevia, G., Trevino, M., Bertocchi, I., Gruart, A., et al. (2013). Role of motor cortex NMDA receptors in learningdependent synaptic plasticity of behaving mice. Nat. Commun. 4:2258. doi: $10.1038 /$ ncomms 3258

Hatsopoulos, N. G., and Suminski, A. J. (2011). Sensing with the motor cortex. Neuron 72, 477-487. doi: 10.1016/j.neuron.2011.10.020

Hendricks, H. T., Van Limbeek, J., Geurts, A. C., and Zwarts, M. J. (2002). Motor recovery after stroke: a systematic review of the literature. Arch. Phys. Med. Rehabil. 83, 1629-1637. doi: 10.1053/apmr.2002.35473

Hess, G., Aizenman, C. D., and Donoghue, J. P. (1996). Conditions for the induction of long-term potentiation in layer II/III horizontal connections of the rat motor cortex. J. Neurophysiol. 75, 1765-1778. doi: 10.1152/jn.1996. 75.5.1765

Hinkley, L. B., Krubitzer, L. A., Nagarajan, S. S., and Disbrow, E. A. (2007). Sensorimotor integration in S2, PV, and parietal rostroventral areas of the human sylvian fissure. J. Neurophysiol. 97, 1288-1297. doi: 10.1152/jn. 00733.2006

Hiraba, H., Yamaguchi, Y., Satoh, H., Ishibashi, Y., and Iwamura, Y. (2000). Deficits of masticatory movements caused by lesions in the orofacial somatosensory cortex of the awake cat. Somatosens. Mot. Res. 17, 361-372. doi: 10.1080/0899022002000202239

Hooks, B. M., Lin, J. Y., Guo, C., and Svoboda, K. (2015). Dual-channel circuit mapping reveals sensorimotor convergence in the primary motor cortex. J. Neurosci. 35, 4418-4426. doi: 10.1523/jneurosci.3741-14.2015

Hooks, B. M., Mao, T., Gutnisky, D. A., Yamawaki, N., Svoboda, K., and Shepherd, G. M. (2013). Organization of cortical and thalamic input to pyramidal neurons in mouse motor cortex. J. Neurosci. 33, 748-760. doi: 10.1523/JNEUROSCI.4338-12.2013

Huber, D., Gutnisky, D. A., Peron, S., O’Connor, D. H., Wiegert, J. S., Tian, L., et al. (2012). Multiple dynamic representations in the motor cortex during sensorimotor learning. Nature 484, 473-478. doi: 10.1038/nature 11039

Huber, R., Ghilardi, M. F., Massimini, M., Ferrarelli, F., Riedner, B. A., Peterson, M. J., et al. (2006). Arm immobilization causes cortical plastic changes and locally decreases sleep slow wave activity. Nat. Neurosci. 9, 1169-1176. doi: $10.1038 / \mathrm{nn} 1758$

Huntley, G. W. (1997). Correlation between patterns of horizontal connectivity and the extend of short-term representational plasticity in rat motor cortex. Cereb. Cortex 7, 143-156. doi: 10.1093/cercor/7.2.143

Iriki, A., Pavlides, C., Keller, A., and Asanuma, H. (1989). Long-term potentiation in the motor cortex. Science 245, 1385-1387. doi: 10.1126/science.2551038

Jabbur, S. J., and Towe, A. L. (1961). Cortical excitation of neurons in dorsal column nuclei of cat, including an analysis of pathways. J. Neurophysiol. 24, 499-509. doi: 10.1152/jn.1961.24.5.499

Jebsen, R. H., Taylor, N., Trieschmann, R. B., Trotter, M. J., and Howard, L. A. (1969). An objective and standardized test of hand function. Arch. Phys. Med. Rehabil. 50, 311-319.

Jørgensen, H. S., Nakayama, H., Raaschou, H. O., Vive-Larsen, J., Støier, M., and Olsen, T. S. (1995). Outcome and time course of recovery in stroke. Part II: time course of recovery. The copenhagen stroke study. Arch. Phys. Med. Rehabil. 76, 406-412. doi: 10.1016/s0003-9993(95)80568-0

Kaas, J. H., Gharbawie, O. A., and Stepniewska, I. (2011). The organization and evolution of dorsal stream multisensory motor pathways in primates. Front. Neuroanat. 5:34. doi: 10.3389/fnana.2011.00034

Kalaska, J. F. (1996). Parietal cortex area 5 and visuomotor behavior. Can. J. Physiol. Pharmacol. 74, 483-498. doi: 10.1139/y96-040

Kaneko, T., Caria, M. A., and Asanuma, H. (1994a). Information processing within the motor cortex. I. Responses of morphologically identified motor cortical cells to stimulation of the somatosensory cortex. J. Comp. Neurol. 345, 161-171. doi: 10.1002/cne.903450202

Kaneko, T., Caria, M. A., and Asanuma, H. (1994b). Information processing within the motor cortex. II. Intracortical connections between neurons receiving somatosensory cortical input and motor output neurons of the cortex. J. Comp. Neurol. 345, 172-184. doi: 10.1002/cne.903450203

Karabanov, A., Jin, S. H., Joutsen, A., Poston, B., Aizen, J., Ellenstein, A., et al. (2012). Timing-dependent modulation of the posterior parietal cortexprimary motor cortex pathway by sensorimotor training. J. Neurophysiol. 107, 3190-3199. doi: 10.1152/jn.01049.2011

Kaskan, P. M., and Kaas, J. H. (2007). Cortical connections of the middle temporal and the middle temporal crescent visual areas in prosimian galagos (Otolemur garnetti). Anat. Rec. 290, 349-366. doi: 10.1002/ar.20440

Kida, H., Tsuda, Y., Ito, N., Yamamoto, Y., Owada, Y., Kamiya, Y., et al. (2016). Motor training promotes both synaptic and intrinsic plasticity of layer ii/iii pyramidal neurons in the primary motor cortex. Cereb. Cortex 26, 3494-3507. doi: 10.1093/cercor/bhw134

Kim, S. S., Gomez-Ramirez, M., Thakur, P. H., and Hsiao, S. S. (2015). Multimodal interactions between proprioceptive and cutaneous signals in primary somatosensory cortex. Neuron 86, 555-566. doi: 10.1016/j.neuron. 2015.03.020 
Kirsch, E., Rivlis, G., and Schieber, M. H. (2014). Primary motor cortex neurons during individuated finger and wrist movements: correlation of spike firing rates with the motion of individual digits versus their principal components. Front. Neurol. 5:70. doi: 10.3389/fneur.2014.00070

Kleim, J. A., Barbay, S., and Nudo, R. J. (1998). Functional reorganization of the rat motor cortex following motor skill learning. J. Neurophysiol. 80, 3321-3325. doi: 10.1152/jn.1998.80.6.3321

Kleim, J. A., Chan, S., Pringle, E., Schallert, K., Procaccio, V., Jimenez, R., et al. (2006). BDNF val66met polymorphism is associated with modified experiencedependent plasticity in human motor cortex. Nat. Neurosci. 9, 735-737. doi: $10.1038 / \mathrm{nn} 1699$

Kleim, J. A., and Jones, T. A. (2008). Principles of experience-dependent neural plasticity: implications for rehabilitation after brain damage. J. Speech Lang. Hear. Res. 51, S225-S239. doi: 10.1044/1092-4388(2008/018)

Koch, G., Cercignani, M., Pecchioli, C., Versace, V., Oliveri, M., Caltagirone, C., et al. (2010). In vivo definition of parieto-motor connections involved in planning of grasping movements. Neuroimage 51, 300-312. doi: 10.1016/j. neuroimage.2010.02.022

Körding, K. P., and Wolpert, D. M. (2004). Bayesian integration in sensorimotor learning. Nature 427, 244-247. doi: 10.1038/nature02169

Krakauer, J. W. (2006). Motor learning: its relevance to stroke recovery and neurorehabilitation. Curr. Opin. Neurol. 19, 84-90. doi: 10.1097/01.wco. 0000200544.29915.cc

Kuehn, E., Dinse, J., Jakobsen, E., Long, X., Schafer, A., Bazin, P. L., et al. (2017). Body topography parcellates human sensory and motor cortex. Cereb. Cortex 27, 3790-3805. doi: 10.1093/cercor/bhx026

Kuramoto, E., Furuta, T., Nakamura, K. C., Unzai, T., Hioki, H., and Kaneko, T. (2009). Two types of thalamocortical projections from the motor thalamic nuclei of the rat: a single neuron-tracing study using viral vectors. Cereb. Cortex 19, 2065-2077. doi: 10.1093/cercor/bhn231

Kwakkel, G., Kollen, B. J., van der Grond, J., and Prevo, A. J. (2003). Probability of regaining dexterity in the flaccid upper limb: impact of severity of paresis and time since onset in acute stroke. Stroke 34, 2181-2186. doi: 10.1161/01.STR. 0000087172.16305.CD

Lai, S. M., Studenski, S., Duncan, P. W., and Perera, S. (2002). Persisting consequences of stroke measured by the stroke impact scale. Stroke 33, 1840-1844. doi: 10.1161/01.str.0000019289.15440.f2

Lang, C. E., Bland, M. D., Bailey, R. R., Schaefer, S. Y., and Birkenmeier, R. L. (2013). Assessment of upper extremity impairment, function and activity after stroke: foundations for clinical decision making. J. Hand Ther. 26, 104-114. doi: 10.1016/j.jht.2012.06.005

Lang, C. E., and Schieber, M. H. (2003). Differential impairment of individuated finger movements in humans after damage to the motor cortex or the corticospinal tract. J. Neuroinflammation 90, 1160-1170. doi: 10.1152/jn.00 130.2003

Langer, N., Hänggi, J., Müller, N. A., Simmen, H. P., and Jäncke, L. (2012). Effects of limb immobilization on brain plasticity. Neurology 78, 182-188. doi: 10.1212/WNL.0b013e31823fcd9c

Lawrence, D. G., and Kuypers, H. G. (1968). The functional organization of the motor system in the monkey. I. The effects of bilateral pyramidal lesions. Brain 91, 1-14. doi: 10.1093/brain/91.1.1

Lee, K. B., Lim, S. H., Kim, K. H., Kim, K. J., Kim, Y. R., Chang, W. N., et al. (2015). Six-month functional recovery of stroke patients: a multi-time-point study. Int. J. Rehabil. Res. 38, 173-180. doi: 10.1097/MRR.0000000000000108

Lemon, R. N. (2008). Descending pathways in motor control. Annu. Rev. Neurosci. 31, 195-218. doi: 10.1146/annurev.neuro.31.060407.125547

Lemon, R. N., Mantel, G. W., and Muir, R. B. (1986). Corticospinal facilitation of hand muscles during voluntary movement in the conscious monkey. J. Physiol. 381, 497-527. doi: 10.1113/jphysiol.1986.sp016341

Liang, M., Mouraux, A., and Iannetti, G. D. (2011). Parallel processing of nociceptive and non-nociceptive somatosensory information in the human primary and secondary somatosensory cortices: evidence from dynamic causal modeling of functional magnetic resonance imaging data. J. Neurosci. 31, 8976-8985. doi: 10.1523/jneurosci.6207-10.2011

Liao, L. R., Huang, M., Lam, F. M., and Pang, M. Y. (2014). Effects of whole-body vibration therapy on body functions and structures, activity and participation poststroke: a systematic review. Phys. Ther. 94, 1232-1251. doi: 10.2522/ptj. 20130366
Lin, L. D., Murray, G. M., and Sessle, B. J. (1993). The effect of bilateral cold block of the primate face primary somatosensory cortex on the performance of trained tongue-protrusion task and biting tasks. J. Neurophysiol. 70, 985-996. doi: 10.1152/jn.1993.70.3.985

Lincoln, N. B., Jackson, J. M., and Adams, S. A. (1998). Reliability and revision of the nottingham sensory assessment for stroke patients. Physiotherapy 84, 358-365. doi: 10.1016/s0031-9406(05)61454-x

Lüscher, C., and Malenka, R. C. (2012). NMDA receptor-dependent long-term potentiation and long-term depression (LTP/LTD). Cold Spring Harb. Perspect. Biol. 4:a005710. doi: 10.1101/cshperspect.a005710

Mahan, M. Y., and Georgopoulos, A. P. (2013). Motor directional tuning across brain areas: directional resonance and the role of inhibition for directional accuracy. Front. Neural. Circuits 7:92. doi: 10.3389/fncir.2013.00092

Makino, H., Hwang, E. J., Hedrick, N. G., and Komiyama, T. (2016). Circuit mechanisms of sensorimotor learning. Neuron 92, 705-721. doi: 10.1016/j. neuron.2016.10.029

Makris, N., Kennedy, D. N., Mcinerney, S., Sorensen, A. G., Wang, R., Caviness, V. S. Jr., et al. (2005). Segmentation of subcomponents within the superior longitudinal fascicle in humans: a quantitative, in vivo, DT-MRI study. Cereb. Cortex 15, 854-869. doi: 10.1093/cercor/bhh186

Mao, T., Kusefoglu, D., Hooks, B. M., Huber, D., Petreanu, L., and Svoboda, K. (2011). Long-range neuronal circuits underlying the interaction between sensory and motor cortex. Neuron 72, 111-123. doi: 10.1016/j.neuron.2011. 07.029

Martinez-Lorenzana, G., Machín, R., and Avendaño, C. (2001). Definite segregation of cortical neurons projecting to the dorsal column nuclei in the rat. Neuroreport 12, 413-416. doi: 10.1097/00001756-200102120-00044

Mathis, M. W., Mathis, A., and Uchida, N. (2017). Somatosensory cortex plays an essential role in forelimb motor adaptation in mice. Neuron 93, 1493.e6-1503.e6. doi: 10.1016/j.neuron.2017.02.049

Meehan, S. K., Dao, E., Linsdell, M. A., and Boyd, L. A. (2011). Continuous theta burst stimulation over the contralesional sensory and motor cortex enhances motor learning post-stroke. Neurosci. Lett. 500, 26-30. doi: 10.1016/j.neulet. 2011.05.237

Meyer, S., Karttunen, A. H., Thijs, V., Feys, H., and Verheyden, G. (2014). How do somatosensory deficits in the arm and hand relate to upper limb impairment, activity, and participation problems after stroke? A systematic review. Phys. Ther. 94, 1220-1231. doi: 10.2522/ptj.20130271

Milliken, G. W., Plautz, E. J., and Nudo, R. J. (2013). Distal forelimb representations in primary motor cortex are redistributed after forelimb restriction: a longitudinal study in adult squirrel monkeys. J. Neurophysiol. 109, 1268-1282. doi: 10.1152/jn.00044.2012

Mo, C., and Sherman, S. M. (2019). A sensorimotor pathway via higherorder thalamus. J. Neurosci. 39, 692-704. doi: 10.1523/JNEUROSCI.146718.2018

Muellbacher, W., Richards, C., Ziemann, U., Wittenberg, G., Weltz, D., Boroojerdi, B., et al. (2002a). Improving hand function in chronic stroke. Arch. Neurol. 59, 1278-1282. doi: 10.1001/archneur.59.8.1278

Muellbacher, W., Ziemann, U., Wissel, J., Dang, N., Kofler, M., Facchini, S., et al. (2002b). Early consolidation in human primary motor cortex. Nature 415, 640-644. doi: 10.1038/nature712

Mulliken, G. H., Musallam, S., and Andersen, R. A. (2008). Forward estimation of movement state in posterior parietal cortex. Proc. Natl. Acad. Sci. U S A 105, 8170-8177. doi: $10.1073 /$ pnas.0802602105

Murphy, T. H., and Corbett, D. (2009). Plasticity during stroke recovery: from synapse to behaviour. Nat. Rev. Neurosci. 10, 861-872. doi: 10.1038/ nrn2735

Mutha, P. K., Sainburg, R. L., and Haaland, K. Y. (2011). Left parietal regions are critical for adaptive visuomotor control. J. Neurosci. 31, 6972-6981. doi: 10.1523/JNEUROSCI.6432-10.2011

Nagy, A., Eördegh, G., Paróczy, Z., Márkus, Z., and Benedek, G. (2006). Multisensory integration in the basal ganglia. Eur. J. Neurosci. 24, 917-924. doi: 10.1111/j.1460-9568.2006.04942.x

Nudo, R. J. (2013). Recovery after brain injury: mechanisms and principles. Front. Hum. Neurosci. 7:887. doi: 10.3389/fnhum.2013.00887

Nudo, R. J., Friel, K. M., and Delia, S. W. (2000). Role of sensory deficits in motor impairments after injury to primary motor cortex. Neuropharmacology 39, 733-742. doi: 10.1016/s0028-3908(99)00254-3 
Nudo, R. J., Milliken, G. W., Jenkins, W. M., and Merzenich, M. M. (1996a). Usedependent alterations of movement representations in primary motor cortex of adult squirrel monkeys. J. Neurosci. 16, 785-807. doi: 10.1523/JNEUROSCI. 16-02-00785.1996

Nudo, R. J., Wise, B. M., SiFuentes, F., and Milliken, G. W. (1996b). Neural substrates for the effects of rehabilitative training on motor recovery after ischemic infarct. Science 272, 1791-1794. doi: 10.1126/science.272.52 69.1791

Ohno, S., Kuramoto, E., Furuta, T., Hioki, H., Tanaka, Y. R., Fujiyama, F., et al. (2012). A morphological analysis of thalamocortical axon fibers of rat posterior thalamic nuclei: a single neuron tracing study with viral vectors. Cereb. Cortex 22, 2840-2857. doi: 10.1093/cercor/bhr356

Opie, G. M., Evans, A., Ridding, M. C., and Semmler, J. G. (2016). Short-term immobilization influences use-dependent cortical plasticity and fine motor performance. Neuroscience 330, 247-256. doi: 10.1016/j.neuroscience.2016. 06.002

Ovbiagele, B., Goldstein, L. B., Higashida, R. T., Howard, V. J., Johnston, S. C., Khavjou, O. A., et al. (2013). Forecasting the future of stroke in the United States: a policy statement from the American Heart Association and American Stroke Association. Stroke 44, 2361-2375. doi: 10.1161/STR.0b013e31829 $734 \mathrm{f} 2$

Paik, N. J., and Yang, E. (2014). Role of GABA plasticity in stroke recovery. Neural Regen. Res. 9, 2026-2028. doi: 10.4103/1673-5374.147920

Papale, A. E., and Hooks, B. M. (2018). Circuit changes in motor cortex during motor skill learning. Neuroscience 368, 283-297. doi: 10.1016/j.neuroscience. 2017.09.010

Park, Y. J., Park, S. W., and Lee, H. S. (2018). Comparison of the effectiveness of whole body vibration in stroke patients: a meta-analysis. Biomed. Res. Int. 2018:5083634. doi: 10.1155/2018/5083634

Pavlides, C., Miyashita, E., and Asanuma, H. (1993). Projection from the sensory to the motor cortex is important in learning motor skills in the monkey. J. Neurophysiol. 70, 733-741. doi: 10.1152/jn.1993.70.2.733

Pellegrini-Giampietro, D. E. (2003). The distinct role of mGlul receptors in post-ischemic neuronal death. Trends Pharmacol. Sci. 24, 461-470. doi: 10.1016/s0165-6147(03)00231-1

Penfield, W., and Boldrey, E. (1937). Somatic motor and sensory representation in thecerebral cortex of man as studied by electrical stimulation. Brain 60 , 389-443. doi: 10.1093/brain/60.4.389

Plautz, E. J., Milliken, G. W., and Nudo, R. J. (2000). Effects of repetitive motor training on movement representations in adult squirrel monkeys: role of use versus learning. Neurobiol. Learn. Mem. 74, 27-55. doi: 10.1006/nlme. 1999.3934

Pons, T. P., Garraghty, P. E., Ommaya, A. K., Kaas, J. H., Taub, E., and Mishkin, M. (1991). Massive cortical reorganization after sensory deafferentation in adult macaques. Science 252, 1857-1860. doi: 10.1126/science.1843843

Proville, R. D., Spolidoro, M., Guyon, N., Dugué, G. P., Selimi, F., Isope, P., et al. (2014). Cerebellum involvement in cortical sensorimotor circuits for the control of voluntary movements. Nat. Neurosci. 17, 1233-1239. doi: 10.1038/nn.3773

Prud'homme, M. J., and Kalaska, J. F. (1994). Proprioceptive activity in primate primary somatosensory cortex during active arm reaching movements. J. Neurophysiol. 72, 2280-2301. doi: 10.1152/jn.1994.72.5.2280

Ragert, P., Nierhaus, T., Cohen, L. G., and Villringer, A. (2011). Interhemispheric interactions between the human primary somatosensory cortices. PLoS One 6:e16150. doi: 10.1371/journal.pone.0016150

Raghavan, P. (2015). Upper limb motor impairment after stroke. Phys. Med. Rehabil. Clin. N. Am. 26, 599-610. doi: 10.1016/j.pmr.2015. 06.008

Rathelot, J. A., and Strick, P. L. (2009). Subdivisions of primary motor cortex based on cortico-motoneuronal cells. Proc. Natl. Acad. Sci. U S A 106, 918-923. doi: 10.1073/pnas.0808362106

Rathelot, J. A., Dum, R. P., and Strick, P. L. (2017). Posterior parietal cortex contains a command apparatus for hand movements. Proc. Natl. Acad. Sci. U S A 114, 4255-4260. doi: 10.1073/pnas.1608132114

Riemann, B. L., Myers, J. B., and Lephart, S. M. (2002). Sensorimotor system measurement techniques. J. Athl. Train. 37, 85-98.

Rioult-Pedotti, M. S., Friedman, D., and Donoghue, J. P. (2000). Learning-induced LTP in neocortex. Science 290, 533-536. doi: 10.1126/science.290.5491.533
Robertson, E. M. (2004). Skill learning: putting procedural consolidation in context. Curr. Biol. 14, R1061-R1063. doi: 10.1016/j.cub.2004. 11.048

Rocco-Donovan, M., Ramos, R. L., Giraldo, S., and Brumberg, J. C. (2011). Characteristics of synaptic connections between rodent primary somatosensory and motor cortices. Somatosens. Mot. Res. 28, 63-72. doi: 10.3109/08990220. 2011.606660

Rosa, M. G., Palmer, S. M., Gamberini, M., Burman, K. J., Yu, H. H., Reser, D. H., et al. (2009). Connections of the dorsomedial visual area: pathways for early integration of dorsal and ventral streams in extrastriate cortex. J. Neurosci. 29, 4548-4563. doi: 10.1523/JNEUROSCI.0529-09.2009

Rosenkranz, K., and Rothwell, J. C. (2006). Differences between the effects of three plasticity inducing protocols on the organization of the human motor cortex. Eur. J. Neurosci. 23, 822-829. doi: 10.1111/j.1460-9568.2006. 04605.x

Rosenkranz, K., and Rothwell, J. C. (2012). Modulation of proprioceptive integration in the motor cortex shapes human motor learning. J. Neurosci. 32, 9000-9006. doi: 10.1523/JNEUROSCI.0120-12.2012

Rosenkranz, K., Seibel, J., Kacar, A., and Rothwell, J. (2014). Sensorimotor deprivation induces interdependent changes in excitability and plasticity of the human hand motor cortex. J. Neurosci. 34, 7375-7382. doi: 10.1523/JNEUROSCI.5139-13.2014

Rosenzweig, E. S., Brock, J. H., Culbertson, M. D., Lu, P., Moseanko, R., Edgerton, V. R., et al. (2009). Extensive spinal decussation and bilateral termination of cervical corticospinal projections in rhesus monkeys. J. Comp. Neurol. 513, 151-163. doi: 10.1002/cne.21940

Sabes, P. N. (2011). Sensory integration for reaching: models of optimality in the context of behavior and the underlying neural circuits. Prog. Brain Res. 191, 195-209. doi: 10.1016/B978-0-444-53752-2.00004-7

Sacco, R. L., Kasner, S. E., Broderick, J. P., Caplan, L. R., Connors, J. J., Culebras, A., et al. (2013). An updated definition of stroke for the 21st century: a statement for healthcare professionals from the American Heart Association/American Stroke Association. Stroke 44, 2064-2089. doi: 10.1161/STR.0b013e318296aeca

Sakata, H., Taira, M., Murata, A., and Mine, S. (1995). Neural mechanisms of visual guidance of hand action in the parietal cortex of the monkey. Cereb. Cortex 5 , 429-438. doi: 10.1093/cercor/5.5.429

Sanes, J. N., and Donoghue, J. P. (2000). Plasticity and primary motor cortex. Annu. Rev. Neurosci. 23, 393-415. doi: 10.1146/annurev.neuro.23.1.393

Sanes, J. N., Suner, S., Lando, J. F., and Donoghue, J. P. (1988). Rapid reorganization of adult rat motor cortex somatic representation patterns after motor nerve injury. Proc. Natl. Acad. Sci. U S A 85, 2003-2007. doi: 10.1073/pnas.85.6.2003

Schieber, M. H. (2011). Dissociating motor cortex from the motor. J. Physiol. 589, 5613-5624. doi: 10.1113/jphysiol.2011.215814

Schwartz-Bloom, R. D., and Sah, R. (2001). $\gamma$-Aminobutyric $\operatorname{acid}_{A}$ neurotransmission and cerebral ischemia. J. Neurochem. 77, 353-371. doi: $10.1046 / j .1471-4159.2001 .00274 . x$

Scott, S. H., and Dukelow, S. P. (2011). Potential of robots as next-generation technology for clinical assessment of neurological disorders and upper-limb therapy. J. Rehabil. Res. Dev. 48, 335-353. doi: 10.1682/jrrd.2010. 04.0057

Seidler, R. D., Kwak, Y., Fling, B. W., and Bernard, J. A. (2013). Neurocognitive mechanisms of error-based motor learning. Adv. Exp. Med. Biol. 782, 39-60. doi: 10.1007/978-1-4614-5465-6_3

Semrau, J. A., Herter, T. M., Scott, S. H., and Dukelow, S. P. (2018). Vision of the upper limb fails to compensate for kinesthetic impairments in subacute stroke. Cortex 109, 245-259. doi: 10.1016/j.cortex.2018.09.022

Sens, E., Knorr, C., Preul, C., Meissner, W., Witte, O. W., Miltner, W. H., et al. (2013). Differences in somatosensory and motor improvement during temporary functional deafferentation in stroke patients and healthy subjects. Behav. Brain Res. 252, 110-116. doi: 10.1016/j.bbr.2013.05.048

Sens, E., Teschner, U., Meissner, W., Preul, C., Huonker, R., Witte, O. W., et al. (2012). Effects of temporary functional deafferentation on the brain, sensation, and behavior of stroke patients. J. Neurosci. 32, 11773-11779. doi: 10.1523/JNEUROSCI.5912-11.2012

Shadmehr, R., Smith, M. A., and Krakauer, J. W. (2010). Error correction, sensory prediction, and adaptation in motor control. Annu. Rev. Neurosci. 33, 89-108. doi: 10.1146/annurev-neuro-060909-153135 
Shmuelof, L., Krakauer, J. W., and Mazzoni, P. (2012). How is a motor skill learned? Change and invariance at the levels of task success and trajectory control. J. Neurophysiol. 108, 578-594. doi: 10.1152/jn. 00856.2011

Snyder, L. H., Batista, A. P., and Andersen, R. A. (1997). Coding of intention in the posterior parietal cortex. Nature 386, 167-170. doi: 10.1038/386167a0

Sober, S. J., and Sabes, P. N. (2003). Multisensory integration during motor planning. J. Neurosci. 23, 6982-6992. doi: 10.1523/JNEUROSCI.23-18-06 982.2003

Spranger, M. D., Krishnan, A. C., Levy, P. D., O'Leary, D. S., and Smith, S. A. (2015). Blood flow restriction training and the exercise pressor reflex: a call for concern. Am. J. Physiol. Heart Circ. Physiol. 309, H1440-H1452. doi: 10.1152/ajpheart.00208.2015

Staines, W. R., Black, S. E., Graham, S. J., and McIlroy, W. E. (2002). Somatosensory gating and recovery from stroke involving the thalamus. Stroke 33, 2642-2651. doi: 10.1161/01.str.0000032552.40405.40

Stepniewska, I., Cerkevich, C. M., Fang, P. C., and Kaas, J. H. (2009). Organization of the posterior parietal cortex in galagos: II. Ipsilateral cortical connections of physiologically identified zones within anterior sensorimotor region. J. Comp. Neurol. 517, 783-807. doi: 10.1002/cne.22190

Stepniewska, I., Preuss, T. M., and Kaas, J. H. (1993). Architectonics, somatotopic organization, and ipsilateral cortical connections of the primary motor area (M1) of owl monkeys. J. Comp. Neurol. 330, 238-271. doi: 10.1002/cne. 903300207

Tokimura, H., Di Lazzaro, V., Tokimura, Y., Oliviero, A., Profice, P., Insola, A., et al. (2000). Short latency inhibition of human hand motor cortex by somatosensory input from the hand. J. Physiol. 523, 503-513. doi: 10.1111/j. 1469-7793.2000.t01-1-00503.x

Viaro, R., Budri, M., Parmiani, P., and Franchi, G. (2014). Adaptive changes in the motor cortex during and after longterm forelimb immobilization in adult rats. J. Physiol. 592, 2137-2152. doi: 10.1113/jphysiol.2013.268821

Viganò, L., Fornia, L., Rossi, M., Howells, H., Leonetti, A., Puglisi, G., et al. (2019). Anatomo-functional characterisation of the human "hand-knob": a direct electrophysiological study. Cortex 113, 239-254. doi: 10.1016/j.cortex. 2018.12.011

von Holst, E., and Mittelstaedt, H. (1950). The reafference principle: interaction between the cnetral nervous system and the periphery. Die Naturwissenschaften 37, 464-476. doi: 10.1007/BF00622503

Walcott, B. P., Miller, J. C., Kwon, C. S., Sheth, S. A., Hiller, M., Cronin, C. A., et al. (2014). Outcomes in severe middle cerebral artery ischemic stroke. Neurocrit. Care 21, 20-26. doi: 10.1007/s12028-013-9838-x

Whitlock, J. R. (2017). Posterior parietal cortex. Curr. Biol. 27, R691-R695. doi: 10.1016/j.cub.2017.06.007

Whitt, J. L., Petrus, E., and Lee, H. K. (2014). Experience-dependent homeostatic synaptic plasticity in neocortex. Neuropharmacology 78, 45-54. doi: 10.1016/j. neuropharm.2013.02.016

Winters, C., van Wegen, E. E., Daffertshofer, A., and Kwakkel, G. (2015). Generalizability of the proportional recovery model for the upper extremity after an ischemic stroke. Neurorehabil. Neural Repair 29, 614-622. doi: $10.1177 / 1545968314562115$

Wolf, S. L. (2007). Revisiting constraint-induced movement therapy: are we too smitten with the mitten? Is all nonuse "learned"? and other quandaries. Phys. Ther. 87, 1212-1223. doi: 10.2522/ptj.20060355

Wolf, S. L., Catlin, P. A., Ellis, M., Archer, A. L., Morgan, B., and Piacentino, A. (2001). Assessing Wolf motor function test as outcome measure for research in patients after stroke. Stroke 32, 1635-1639. doi: 10.1161/01.str. 32.7.1635

Wolpert, D. M., Goodbody, S. J., and Husain, M. (1998). Maintaining internal representations: the role of the human superior parietal lobe. Nat. Neurosci. 1, 529-533. doi: 10.1038/2245

Yamawaki, N., Borges, K., Suter, B. A., Harris, K. D., and Shepherd, G. M. (2014). A genuine layer 4 in motor cortex with prototypical synaptic circuit connectivity. Elife 3:e05422. doi: 10.7554/elife.05422

Yao, D., Yamamura, K., Narita, N., Murray, G. M., and Sessle, B. J. (2002). Effects of reversible cold block of face primary somatosensory cortex on orofacial movements and related face primary motor cortex neuronal activity. Somatosens. Mot. Res. 19, 261-271. doi: 10.1080/08990220210000 37728

Yasuda, T., Fukumura, K., Fukuda, T., Iida, H., Imuta, H., Sato, Y., et al. (2014). Effects of low-intensity, elastic band resistance exercise combined with blood flow restriction on muscle activation. Scand. J. Med. Sci. Sports 24, 55-61. doi: 10.1111/j.1600-0838.2012.01489.x

Zaaimi, B., Edgley, S. A., Soteropoulos, D. S., and Baker, S. N. (2012). Changes in descending motor pathway connectivity after corticospinal tract lesion in macaque monkey. Brain 135, 2277-2289. doi: 10.1093/brain/ aws 115

Zeiler, S. R., Hubbard, R., Gibson, E. M., Zheng, T., Ng, K., O’Brien, R., et al. (2016). Paradoxical motor recovery from a first stroke after induction of a second stroke: reopening a postischemic sensitive period. Neurorehabil. Neural Repair 30, 794-800. doi: 10.1177/1545968315624783

Ziemann, U., Ilić, T. V., Pauli, C., Meintzschel, F., and Ruge, D. (2004). Learning modifies subsequent induction of long-term potentiation-like and long-term depression-like plasticity in human motor cortex. J. Neurosci. 24, 1666-1672. doi: 10.1523/JNEUROSCI.5016-03.2004

Conflict of Interest Statement: The authors declare that the research was conducted in the absence of any commercial or financial relationships that could be construed as a potential conflict of interest.

Copyright (C) 2019 Edwards, King, Buetefisch and Borich. This is an open-access article distributed under the terms of the Creative Commons Attribution License (CC BY). The use, distribution or reproduction in other forums is permitted, provided the original author(s) and the copyright owner(s) are credited and that the original publication in this journal is cited, in accordance with accepted academic practice. No use, distribution or reproduction is permitted which does not comply with these terms. 